\title{
Non-Functionalized Fullerenes and Endofullerenes in Aqueous Dispersions as Superoxide Scavengers
}

\author{
Ivan V. Mikheev ${ }^{1}{ }^{(}$, Madina M. Sozarukova ${ }^{2}$, Elena V. Proskurnina ${ }^{3}{ }^{\circledR}$, Ivan E. Kareev ${ }^{4}$ and \\ Mikhail A. Proskurnin 1,*(iD) \\ 1 Department of Chemistry, Lomonosov Moscow State University, 119991 Moscow, Russia; \\ mikheev.ivan@gmail.com \\ 2 Kurnakov Institute of General and Inorganic Chemistry, Russian Academy of Sciences, 117901 Moscow, \\ Russia; s_madinam@bk.ru \\ 3 Research Centre for Medical Genetics, 115522 Moscow, Russia; proskurnina@gmail.com \\ 4 Institute of Problems of Chemical Physics of the Russian Academy of Sciences, Chernogolovka, \\ 142432 Moscow Region, Russia; kareev@icp.ac.ru \\ * Correspondence: proskurnin@gmail.com; Tel.: +7-495-939-4648
}

Academic Editors: Carmelo Corsaro and Enza Fazio Received: 6 May 2020; Accepted: 26 May 2020; Published: 28 May 2020

\begin{abstract}
Endohedral metal fullerene are potential nanopharmaceuticals for MRI; thus, it is important to study their effect on reactive oxygen species (ROS) homeostasis. Superoxide anion radical is one of the key ROS. The reactivity of aqueous dispersions of pristine (non-functionalized) fullerenes and $G d @ C_{82}$ endofullerene have been studied with respect to superoxide in the xanthine/xanthine oxidase chemiluminescence system. It was found that $C_{60}$ and $C_{70}$ in aqueous dispersions react with superoxide as scavengers by a similar mechanism; differences in activity are determined by cluster parameters, primarily the concentration of available, acting molecules at the surface. Gd endofullerene is characterized by a significantly (one-and-a-half to two orders of magnitude) higher reactivity with respect to $\mathrm{C}_{60}$ and $\mathrm{C}_{70}$ and is likely to exhibit nanozyme (SOD-mimic) properties, which can be accounted for by the nonuniform distribution of electron density of the fullerene cage due to the presence of the endohedral atom; however, in the cell model, Gd@ $\mathrm{C}_{82}$ showed the lowest activity compared to $\mathrm{C}_{60}$ and $\mathrm{C}_{70}$, which can be accounted for by its higher affinity for the lipid phase.
\end{abstract}

Keywords: Fullerene aqueous dispersions; non-functionalized (pristine) fullerenes; nanozymes; chemiluminescence; SOD-mimic activity; reactive oxygen species

\section{Introduction}

Reactive oxygen species (ROS) play an important part in regulating many biological processes in living systems $[1,2]$. ROS are closely related to cell proliferation, growth and death, redox signaling, immune function, inflammation, carcinogenesis, ageing, and degenerative processes [3,4]. Among ROS, hydrogen peroxide and superoxide anion radical (SAR) are the two key redox signaling agents generated under the control of growth factors and cytokines by more than 40 enzymes, prominently including NADPH oxidases and the mitochondrial electron-transport chain [5]. Produced in proper amounts, superoxide is a normal and relevant metabolite serving as a signaling molecule. But when overproduced, this radical can initiate lipid peroxidation, protein oxidation, and DNA damage, hence leading to cell dysfunction and death by apoptosis or necrosis [6].

For SAR metabolization, a single enzyme family, superoxide dismutases (SOD), is responsible. They catalyze the dismutation of two SARs to hydrogen peroxide and molecular oxygen as $2 \mathrm{OO}^{\bullet-}+2 \mathrm{H}^{+}=\mathrm{H}_{; 2} \mathrm{O}_{2}+\mathrm{O}_{2}$. SODs are metalloproteins with nickel, iron/manganese, or zinc/copper active centers [7]. As SAR is involved in the inflammation development, SOD mimics can possess 
anti-inflammatory effects [8]. In fact, protective and beneficial roles of SOD enzymes in many diseases have been shown, both preclinically and clinically [9].

The main drawbacks of these natural species are their large size, which hinders cell permeability, their short circulating half-life, antigenicity, and expense. Thus, several low-molecular SOD mimics have been developed to overcome some of these drawbacks [10]. To-day, many comprehensive reviews sum up the knowledge on the properties of compounds with SOD-mimic activity [11,12]. Among these compounds, promising are artificial nanozymes. Recently, they have become increasingly attractive as therapeutic agents because they can be imbued with many target properties and are stable in vivo. One of nanozyme candidates are fullerenes [13], first of all, their functionalized species because structural and electronic parameters of their cages provide various targeted chemical grafting resulting in biochemically active water-soluble derivatives [14]. Such functionalized fullerenes are efficient peroxidase and SOD mimics [15-18].

However, nowadays, the research is focused on non-functionalized (pristine) fullerenes in aqueous dispersions as they are not involved in metabolic processes owing to their open surface without moieties. Pristine fullerenes show a protective antioxidant effect in ROS-dependent experimental models of cell damage [19-25]. Antioxidant effects of aqueous fullerene dispersions (AFD) have also been proved in vivo [26].

Another relevant fullerene nanozyme candidates are endohedral metallofullerenes (endofullerenes). Of particular interest are gadolinium endofullerenes as MRI agents $[27,28]$ because of their efficiency and safety in comparison with commercially available drugs [29]. They can be also used in vivo for inhibiting tumor proliferation and initiating antioxidant defenses [30]. Biocompatibility and safety are even more important for endofullerenes because of their use in MRI and possible metal-releasing cage opening for functionalized species. However, antioxidant and SAR-scavenging properties of non-functionalized endofullerenes have been not thoroughly studied.

Thus, the aim of this paper is to study SOD-mimic activity of aqueous dispersions of non-functionalized fullerenes and gadolinium endofullerenes in in vitro and cell models.

\section{Results}

\subsection{Preparation, Purification, and Characterization of Aqueous Fullerene Dispersions}

Two types of AFDs have been prepared for comparison sake: (1) By direct ultrasound sonication of pristine $\mathrm{C}_{60}, \mathrm{C}_{70}$, and $\mathrm{Gd} @ \mathrm{C}_{82}\left(C_{2 v}\right)$ in ultrapure water and (2) by ultrasound sonication with solvent replacement in ultrapure water. The direct sonication procedure without solubilizing agents was previously developed for the synthesis of fullerene derivatives [31]. Organic solvents (benzene or toluene) may also be used to prepare concentrated and stable solutions of $\mathrm{C}_{60}, \mathrm{C}_{70}$ [32], and $\mathrm{Y} @ \mathrm{C}_{82}$ $\left(C_{2 v}\right)$ through solvent replacement [33]. However, after removing the solvents by ultrasonic-assisted evaporation, traces of harmful organic compounds may cause nanozyme inactivation [34].

We used an immersion ultrasound probe made of titanium. Despite the formation of titania nanoparticles during ultrasonication, this procedure produces efficiently dispersed nanoparticles [35]. According to ICP-AES, a prolonged ultrasound exposure of fullerene $\mathrm{C}_{60}$-water mixtures resulted in the concentration of total titanium as high as $3.50 \pm 0.05 \mathrm{ppm}$. Cellulose syringe filters with a pore diameter of 0.45 and $0.22 \mu \mathrm{m}$ were used to purify the dispersions from titanium. As a result, all the prepared samples contained less than $1 \mathrm{ppm}$ titanium dioxide.

The filtration also improves the optical parameters of AFDs (Figures S1 and S2 in Supplementary Materials), though the fullerene concentrations have been decreased to $50-60 \%$ of the initial (by UV/VIS absorbance [32] for $\mathrm{C}_{60}$ and $\mathrm{C}_{70}$ and ICP-AES for Gd@ $\mathrm{C}_{82}$ ). ATR-FTIR spectra of pristine fullerenes and AFD $C_{60}$ have been recorded (Figures S3 and S4 in Supplementary Materials). The absence of significant functionalization of fullerenes in AFDs has been proved by MALDI [33]. The details of the prepared samples are presented in Table 1. 
Table 1. Concentrations $(c ;)$, size, zeta-potential $(\zeta)$, and cluster parameters of aqueous fullerene dispersions including cluster concentrations $(\hat{c})$, the number of molecules in a cluster $\left(n_{\mathrm{c}}\right)$, the number of molecules at the cluster surface $\left(n_{\mathrm{c}}\right.$, surf $)$, the fraction of active (surface) fullerenes in cluster $(\eta)$, and acting (surface) fullerene concentration (́́, act)

\begin{tabular}{|c|c|c|c|c|c|c|c|c|c|c|}
\hline Fullerene & Preparation Technique & $c ;, \mathrm{mM}$ & $\begin{array}{l}\text { Particle Size after a } \\
0.22 \mu \mathrm{m} \text { Filter, } \mathrm{nm}\end{array}$ & $\begin{array}{c}\zeta \text {-Potential, } \\
\mathrm{mV}\end{array}$ & $\begin{array}{l}\dot{c} \times 10^{-13}, \\
\text { Clusters/L }\end{array}$ & $\begin{array}{c}\dot{c}_{r} \\
\mathrm{pM}\end{array}$ & $n_{\mathrm{c}} \times 10^{-6}$ & $n_{\mathrm{c} \text {,surf }} \times$ & $\eta, \%$ & $\dot{c}^{\prime}$ act, $\mu \mathrm{M}$ \\
\hline $\mathrm{C}_{60}$ & Direct sonication & $0.083^{1}$ & $110 \pm 5$ & $-28.4 \pm 0.2$ & 1.40 & 23.2 & 3.6 & 5.7 & 1.60 & 1.3 \\
\hline $\mathrm{C}_{60}$ & Solvent-replacement sonication & $0.090^{1}$ & $100 \pm 3$ & $-29.0 \pm 0.3$ & 2.01 & 33.5 & 2.7 & 4.7 & 1.76 & 1.6 \\
\hline $\mathrm{C}_{70}$ & Solvent-replacement sonication & $0.077^{1}$ & $111 \pm 3$ & $-30.9 \pm 0.3$ & 2.32 & 38.5 & 2.0 & 3.9 & 1.94 & 1.5 \\
\hline $\mathrm{Gd} @ \mathrm{C}_{82}$ & $\begin{array}{l}\text { Direct sonication of solid } \\
\text { Gd@ } C_{82} \text {-enriched sample }\end{array}$ & $0.022^{2}$ & $95 \pm 5$ & $-32.3 \pm 0.3$ & 6.07 & 100.1 & 0.20 & 0.88 & 4.07 & 0.89 \\
\hline $\mathrm{Gd} @ \mathrm{C}_{82}$ & $\begin{array}{l}\text { Solvent-replacement sonication } \\
\text { of toluene HPLC-grade } \\
\text { Gd@C } 82 \text { solution }\end{array}$ & $0.011^{2}$ & $90 \pm 2$ & $-25.2 \pm 0.3$ & 3.43 & 59.9 & 0.18 & 0.79 & 4.29 & 0.45 \\
\hline
\end{tabular}

${ }^{1}$ measured by UV/vis spectroscopy. ${ }^{2}$ measured by ICP-AES. 


\subsection{Superoxide Scavenging by SOD}

The chemiluminescence (CL) system based on xanthine/xanthine oxidase $(\mathrm{Xa} / \mathrm{XO})$ and lucigenin is widely used for studying superoxide-scavenging potentialities of SOD mimics [36,37]. We have optimized the procedure to achieve reproducible steady-state levels of luminescence intensity and studied the effect of SOD as a reference enzyme (Figure 1).

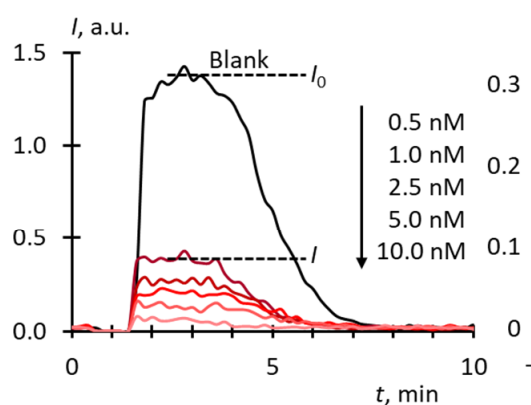

(a)

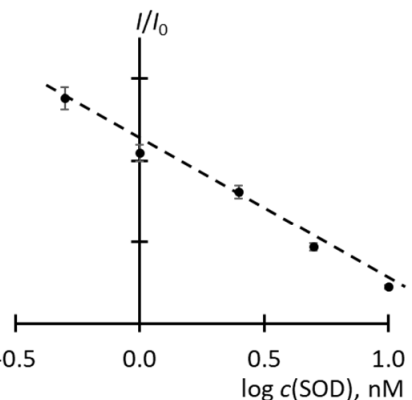

(b)

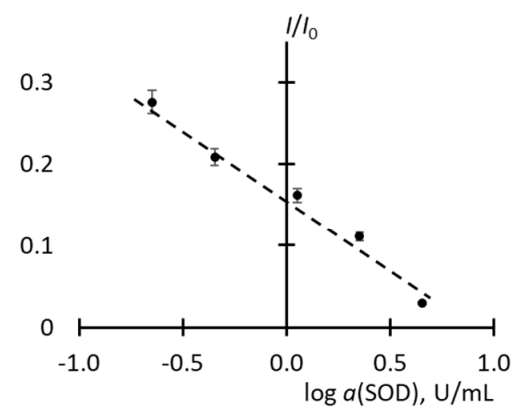

(c)

Figure 1. Oxidation of xanthine $(10 \mu \mathrm{M})$ with xanthine oxidase $(2.2 \mathrm{mU} / \mathrm{mL})$ in the presence of lucigenin $(10 \mu \mathrm{M})$ and various amounts of superoxide dismutases (SOD): (a) Source chemiluminograms, SOD concentrations are shown in the legend; (b) the dependence of the ratio of the stationary CL signal to the stationary signal control experiment $I / I_{0}$ vs. $\log c_{\mathrm{SOD}} ;$ (c) the same plot in $I / I_{0} \mathrm{vs} . \log a_{\mathrm{SOD}}$ coordinates; the total volume, $1000 \mathrm{~mL}$; temperature, $37^{\circ} \mathrm{C}$.

The area under a CL curve is proportional to the number of radicals formed, but in this case, we cannot use it as a measure of SOD antioxidant activity. This could be done if the chemiluminescence after the consumption of the antioxidant resource of SOD had returned to its previous level. However, the luminescence breaks off (the blank curve in Figure 1a), possibly due to the autoactivation of xanthine oxidase by the formed uric acid [38] or hydrogen peroxide [39], which, along with SAR, is a product of reactions catalyzed by xanthine oxidase $[40,41]$. Therefore, to build a calibration curve, we used the ratio of the stationary intensity to the intensity of the blank experiment as a function of log $c_{\mathrm{SOD}}$ (Figure $1 \mathrm{~b}$ ). To discriminate the nature of $\mathrm{CL}$, experiments were carried out with the addition of catalase to $\mathrm{Xa} / \mathrm{XO}$ with lucigenin and luminol (Figure 2). Lucigenin is a CL probe sensitive mainly to SAR, while luminol is sensible to both SAR and hydrogen peroxide [42,43].

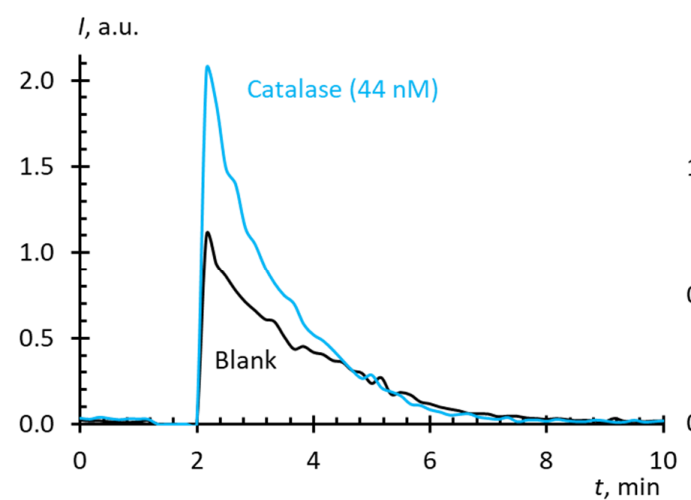

(a)

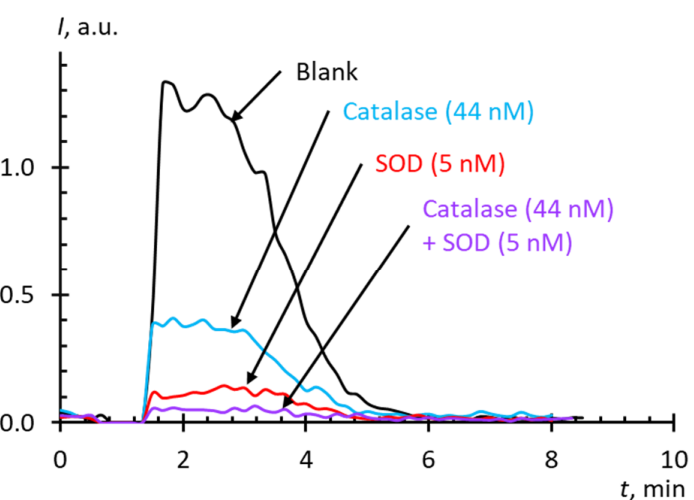

(b)

Figure 2. Chemiluminescence kinetics of xanthine $(10 \mu \mathrm{M})$ oxidation with xanthine oxidase $(2.2 \mathrm{mU} / \mathrm{mL})$ in the presence of catalase $(44 \mathrm{nM}, 27.5 \mathrm{U} / \mathrm{mL})$ and SOD $(5 \mathrm{nM})$ and CL-enhancers: (a) luminol $(20 \mu \mathrm{M})$; (b) lucigenin $(10 \mu \mathrm{M})$; phosphate buffer solution $(100 \mathrm{mM} \mathrm{pH} 7.4)$; the total volume, $1000 \mathrm{~mL}$; temperature, $37^{\circ} \mathrm{C}$. 


\subsection{Blank Experiments}

Titania nanoparticles were present in all AFDs because of the immersion probe technique, and traces of toluene were present in the case of solvent replacement. Blank experiments showed that the effect of titania nanoparticles can be neglected (Figure 3a). However, toluene showed pro-oxidant activity, which depended on the concentration (Figure 3b), which should be involved into the interpretation of experiments with solvent-replacement AFDs.

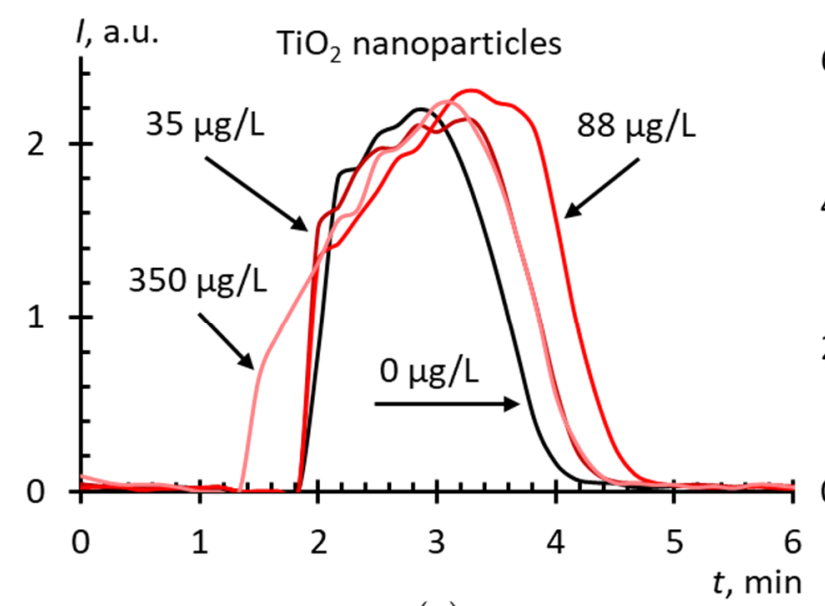

(a)

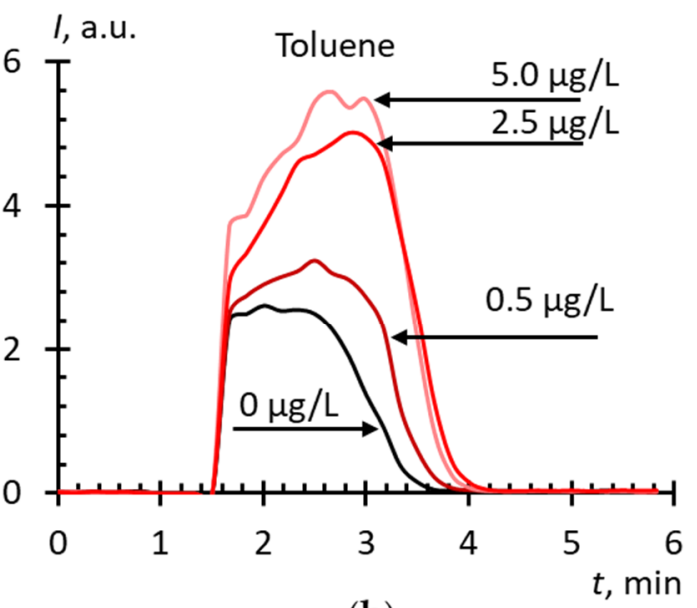

(b)

Figure 3. Chemiluminograms of aqueous dispersions of (a) $\mathrm{TiO}_{2}$ and (b) toluene in phosphate buffer solution $(100 \mathrm{mM} \mathrm{pH} \mathrm{7.4)} \mathrm{+} \mathrm{lucigenin}(10 \mu \mathrm{M})+$ xanthine $(10 \mu \mathrm{M})+$ xanthine oxidase $(2.2 \mathrm{mU} / \mathrm{mL})$; the total volume, $1.000 \mathrm{~mL}$; temperature, $37^{\circ} \mathrm{C}$.

\subsection{Superoxide Scavenging by Fullerenes in Aqueous Dispersions}

The results of studying the superoxide-scavenging properties of $\mathrm{C}_{60}$ AFDs by direct dispergation and with solvent replacement are shown in Figure $4 \mathrm{a}-\mathrm{d}$. The addition of $\mathrm{C}_{60}$ up to $20 \mu \mathrm{M}$; to $\mathrm{Xa} / \mathrm{XO}$ decreases the luminescence that demonstrates their SAR scavenging ability. The equations of calibration curves and the concentration of half-suppression of the signal of the blank experiment (Table 2) show that: (a) $\mathrm{C}_{60}$ in AFD reacts with SAR about $10^{5}$ times less actively than SOD, and (b) an AFD by solvent replacement is a slightly more active scavenger of SAR than an AFD by direct dispergation, even despite of the prooxidant effect of toluene. Recalculation of the dependence from total fullerene concentration to the concentration of acting surface fullerene molecules does not lead to significant changes in the slopes (Table 2).

For $C_{70}$ (Figure 5), $c_{\frac{1}{2}}$ values (Table 2) show that: (a) $C_{70}$ in AFD reacts with SAR about $10^{6}$ times less actively than SOD and nearly five times less actively than $\mathrm{C}_{60}$ in AFD, (b) AFD by solvent replacement is a slightly more active SAR scavenger, as $\mathrm{C}_{60}$. The kinetics of suppressing the blank signal by $C_{70}$ AFD (Figure 5a,c;) is close to that for $C_{60}$ (Figure $4 a, c$ ), but not to the kinetics of SOD action (Figure 1a).

Experiments in the $\mathrm{Xa} / \mathrm{XO}+$ lucigenin system for $\mathrm{Gd} @ \mathrm{C}_{82}$ are shown in Figure $6 \mathrm{a}-\mathrm{d}$. In the system with lucigenin and luminol, the effect of the addition of catalase (Figure 6e,f) was tested. From the $c_{1}$ values (Table 2 ) it follows that (a) Gd@ $\mathrm{C}_{82}$ reacts with SAR approximately $10^{4}$ times less actively than SOD, and this fullerene is about 10-15 times more active than $C_{60}$ and 50 times than $C_{70}$ AFDs; (b) as in the previous two cases, the fullerene obtained by solvent replacement is a slightly more active SAR scavenger. 


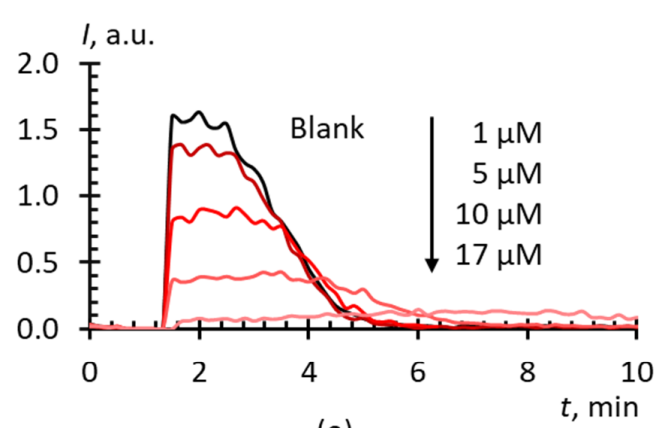

(a)

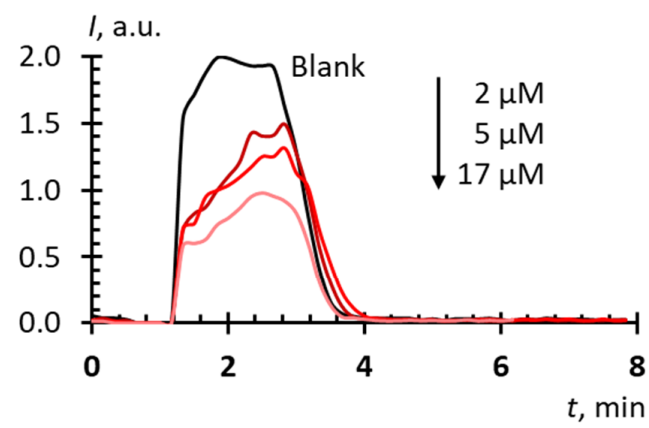

(c)

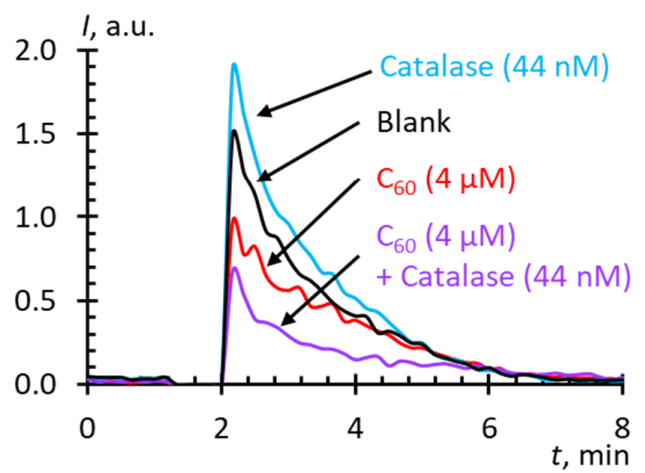

(e)

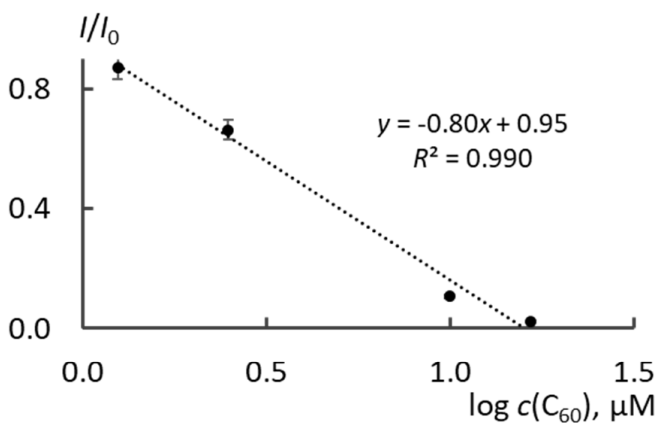

(b)

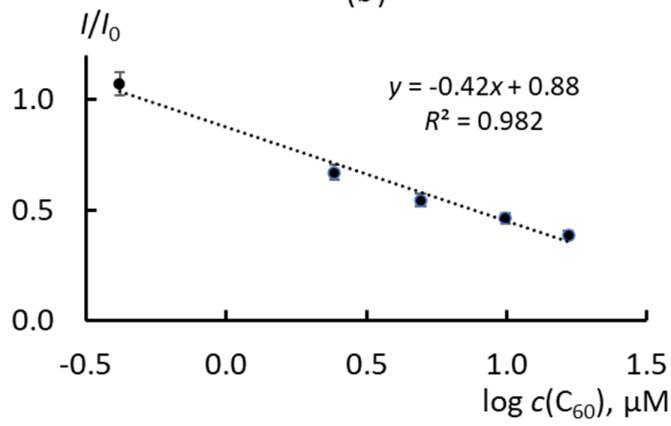

(d)

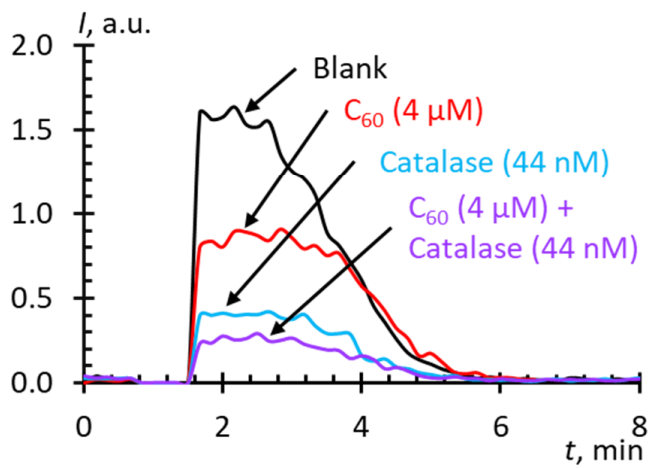

(f)

Figure 4. Effects of aqueous dispersions of $\mathrm{C}_{60}$ on the chemiluminescence kinetics of xanthine $(10 \mu \mathrm{M})$ oxidation with xanthine oxidase $(2.2 \mathrm{mU} / \mathrm{mL})$ : (a) $\mathrm{C}_{60}$ by direct dispergation, lucigenin-enhanced chemiluminescence $(10 \mu \mathrm{M}) ;(\mathbf{b}) \mathrm{C}_{60}$ by direct dispergation, calibration plot of $I / I_{0} \mathrm{vs} . \lg (c)$; (c) $\mathrm{C}_{60}$ by solvent replacement, lucigenin-enhanced chemiluminescence $(10 \mu \mathrm{M}) ;(\mathbf{d}) \mathrm{C}_{60}$ by solvent replacement procedure, calibration plot of $I / I_{0} \mathrm{vs} . \lg (c)$; (e) with catalase $(44 \mathrm{nM}, 27.5 \mathrm{U} / \mathrm{mL})$ added, luminol-enhanced chemiluminescence, $(20 \mu \mathrm{M})$; (f) with catalase $(44 \mathrm{nM}, 27.5 \mathrm{U} / \mathrm{mL})$ added, lucigenin-enhanced chemiluminescence, $(10 \mu \mathrm{M}) ; \mathrm{C}_{60}$ concentrations are given in plots, phosphate buffer solution (100 $\mathrm{mM}$ $\mathrm{pH}$ 7.4); the total volume, $1000 \mathrm{~mL}$; temperature, $37^{\circ} \mathrm{C}$. 
Table 2. Antioxidant capacity of aqueous fullerene dispersions (AFD) $\mathrm{C}_{60}, \mathrm{C}_{70}, \mathrm{Gd} @ \mathrm{C}_{82}$, and $\mathrm{SOD}(n=3, P=0.95)$.

\begin{tabular}{|c|c|c|c|c|}
\hline Sample & $\begin{array}{l}\text { Calibration Functions } I / I_{0} \text { vs.c } \\
\text { (or } a \text { for SOD) }\end{array}$ & $\begin{array}{l}\text { Calibration Functions } I / I_{0} \text { vs. } \\
\text { Active Cluster Concentration } \\
\qquad(\hat{c}, \text { act })\end{array}$ & $\begin{array}{c}\text { Concentration of } \\
\text { Semi-Suppression of } \\
\text { Reference (Blank) CL }\left(c_{1 / 2}\right)\end{array}$ & $\begin{array}{l}\text { Rel. to SOD } \\
\text { Efficiency, } \times 10^{6}\end{array}$ \\
\hline SOD & $\begin{array}{c}I / I_{0}=(-0.18 \pm 0.01) \times a(\mathrm{U} / \mathrm{mL})+ \\
(0.16 \pm 0.03), r=0.9820\end{array}$ & - & $0.03 \pm 0.005 \mathrm{nM}$ & - \\
\hline $\mathrm{AFD} \mathrm{C}_{60}$ (direct dispergation) & $\begin{array}{c}I / I_{0}=(-0.80 \pm 0.09) \times c(\mu \mathrm{M})+ \\
(0.96 \pm 0.06), r=0.9980\end{array}$ & $\begin{array}{c}I / I_{0}=(-0.60 \pm 0.06) \times c(\mu \mathrm{M})- \\
(0.36 \pm 0.06), r=0.9952\end{array}$ & $4.0 \pm 0.1 \mu \mathrm{M}$ & 7.5 \\
\hline AFD C $_{60}$ (solvent replacement) & $\begin{aligned} I / I_{0}= & (-0.42 \pm 0.03) \times c(\mu \mathrm{M})+ \\
& (0.87 \pm 0.5), r=0.9960\end{aligned}$ & $\begin{array}{c}I / I_{0}=(-0.27 \pm 0.03) \times c(\mu \mathrm{M})+ \\
(0.70 \pm 0.22), r=0.9771\end{array}$ & $2.0 \pm 0.4 \mu \mathrm{M}$ & 15 \\
\hline $\mathrm{AFD} \mathrm{C}_{70}$ (direct dispergation) & $\begin{array}{c}I / I_{0}=(-0.30 \pm 0.02) \times c(\mu \mathrm{M})+ \\
\quad(0.85 \pm 0.09), r=0.9860\end{array}$ & $\begin{array}{c}I / I_{0}=(-0.30 \pm 0.02) \times c(\mu \mathrm{M})+ \\
(0.8 \pm 0.0), r=0.9913\end{array}$ & $14.5 \pm 2.1 \mu \mathrm{M}$ & 2 \\
\hline $\mathrm{AFD} \mathrm{C}_{70}$ (solvent replacement) & $\begin{array}{c}I / I_{0}=(-0.94 \pm 0.08) \times c(\mu \mathrm{M})+ \\
(1.34 \pm 0.3), r=0.9980\end{array}$ & $\begin{array}{c}I / I_{0}=(-0.94 \pm 0.08) \times c(\mu \mathrm{M})+ \\
(0.23 \pm 0.07), r=0.9913\end{array}$ & $9.0 \pm 0.7 \mu \mathrm{M}$ & 3 \\
\hline Gd@ $\mathrm{C}_{82}$ (direct dispergation) & $\begin{array}{c}I / I_{0}=(-0.46 \pm 0.3) \times c(\mu \mathrm{M})+ \\
(0.25 \pm 0.05), r=0.9640\end{array}$ & $\begin{array}{c}I / I_{0}=(-0.46 \pm 0.3) \times c(\mu \mathrm{M})+ \\
(0.25 \pm 0.05), r=0.9818\end{array}$ & $0.28 \pm 0.05 \mu \mathrm{M}$ & 100 \\
\hline Gd@ $\mathrm{C}_{82}$ (solvent replacement) & $\begin{array}{c}I / I_{0}=(-0.12 \pm 0.01) \times c(\mu \mathrm{M})+ \\
(0.02 \pm 0.002), r=0.9980\end{array}$ & $\begin{array}{c}/ I_{0}=(-0.12 \pm 0.02) \times c(\mu \mathrm{M})+ \\
(0.13 \pm 0.04), r=0.9998\end{array}$ & $0.07 \pm 0.005 \mu \mathrm{M}$ & 400 \\
\hline
\end{tabular}



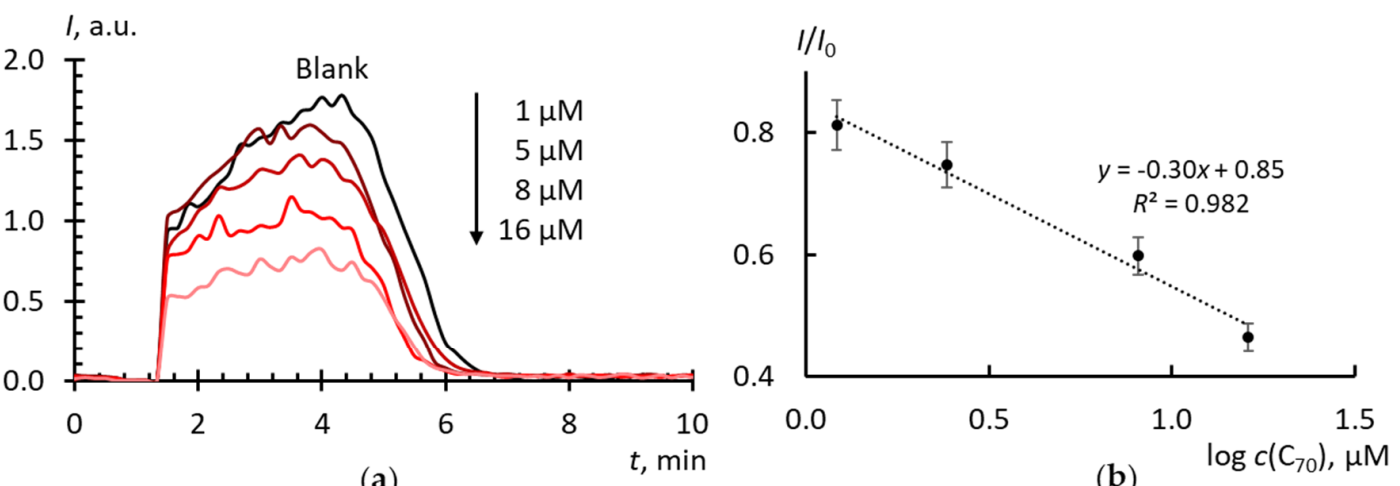

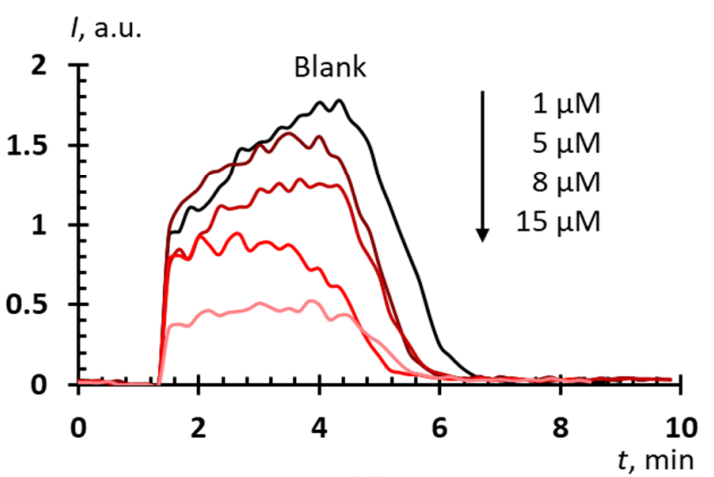

(c)

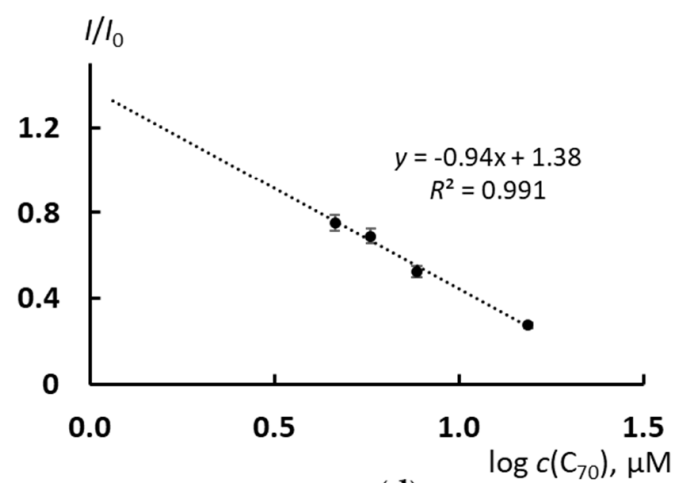

(d)

Figure 5. Effects of $A D F C_{70}$ on the chemiluminescence kinetics of xanthine $(10 \mu \mathrm{M})$ oxidation with xanthine oxidase $(2.2 \mathrm{mU} / \mathrm{mL})$ : (a) $\mathrm{C}_{70}$ was prepared by direct dispergation procedure, lucigenin-enhanced chemiluminescence $(10 \mu \mathrm{M}) ;(\mathbf{b}) \mathrm{C}_{70}$ was prepared by direct dispergation procedure, calibration plot of $I / I_{0}$ vs. $\log (\mathrm{c})$; (c) $C_{70}$ was prepared by solvent replacement procedure, lucigenin-enhanced chemiluminescence $(10 \mu \mathrm{M})$; (d) $\mathrm{C}_{70}$ was prepared by solvent replacement procedure, calibration plot of $I / I_{0}$ vs. $\log (c)$; concentrations of $C_{70}$ are given in plots, phosphate buffer solution (100 $\mathrm{mM} \mathrm{pH} \mathrm{7.4);} \mathrm{the} \mathrm{total} \mathrm{volume,} 1000 \mathrm{~mL}$; temperature, $37^{\circ} \mathrm{C}$.

\subsection{Superoxide Scavenging Potential of Aqueous Fullerene Dispersions in Cells}

Considering the potential use of endofullerenes as contrasting agents for MRI, the next step is the study of superoxide-scavenging properties in cells. It is believed that it is the SOD-like effect of nanopharmaceuticals that can reduce their cyto- and genotoxicity. Such studies may include the study of cytotoxicity using the MTT test, visualization of the permeation of nanoparticles into cells and their distribution based on intrinsic fluorescence by confocal microscopy, visualization of intracellular ROS using, for example, H2DCFH-DA (7'-dichloro-dihydrofluorescein diacetate). Here, we conducted preliminary studies of the SAR-scavenger potential of the fullerenes on human fetal lung fibroblasts using the lucigenin + NADH chemiluminescent system as a model for the generation of intracellular superoxide by cytochrome b5 reductase [44,45].

Figure 7a shows NADH-stimulated lucigenin-enhanced chemiluminescence kinetics in the presence of the AFDs. From the chemiluminograms, the area under the curve for $20 \mathrm{~min}$ was determined, and the degree of suppression of luminescence related to the blank was calculated $\left(K=S / S_{0}\right)$. The lower the $K$ value, the higher the SAR-scavenging potential of the substance. 


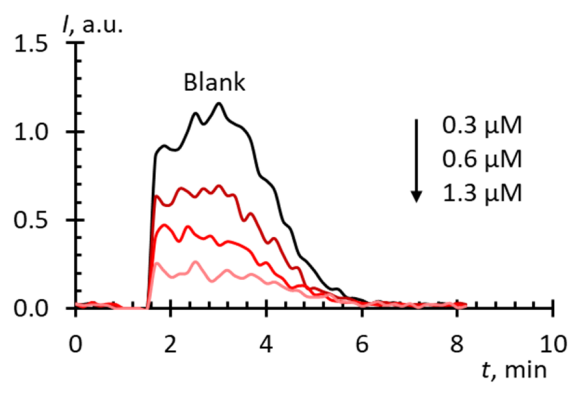

(a)

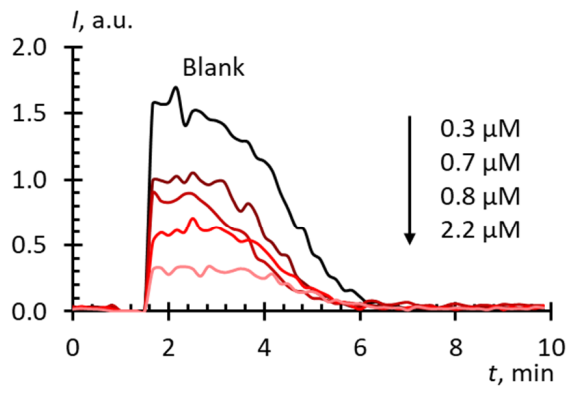

(c)

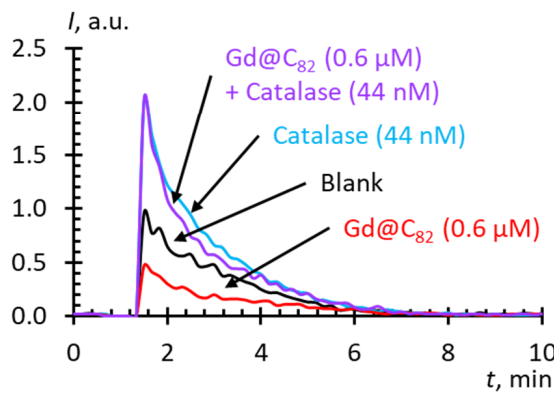

(e)

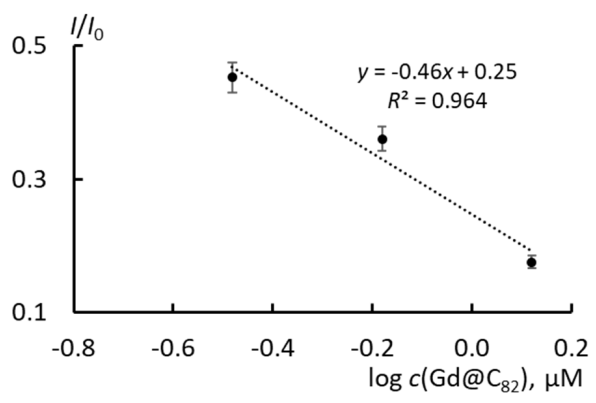

(b)

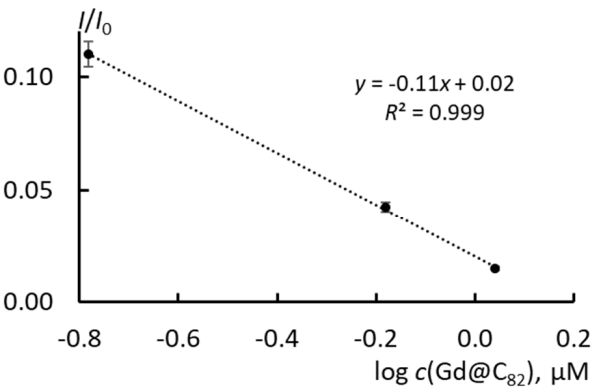

(d)

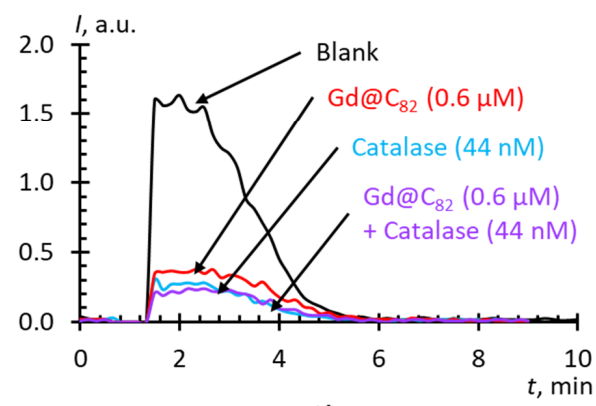

(f)

Figure 6. Effects of $\mathrm{Gd} @ \mathrm{C}_{82}$ on the chemiluminescence kinetics of xanthine $(10 \mu \mathrm{M})$ oxidation with xanthine oxidase $(2.2 \mathrm{mU} / \mathrm{mL})$ : (a) $\mathrm{Gd}_{0} \mathrm{C}_{82}$ by direct dispergation, lucigenin-enhanced chemiluminescence $(10 \mu \mathrm{M}) ;(\mathbf{b}) \mathrm{Gd} @ \mathrm{C}_{82}$ by direct dispergation, calibration plot of $I / I_{0} \mathrm{vs.} \lg (c)$; (c) $\mathrm{Gd} @ \mathrm{C}_{82}$ by solvent replacement, lucigenin-enhanced chemiluminescence $(10 \mu \mathrm{M})$; (d) Gd@ $@ \mathrm{C}_{82}$ by solvent replacement procedure, calibration plot of $I / I_{0} \mathrm{vs} . \lg ($ c); (e) with catalase $(44 \mathrm{nM}, 27.5 \mathrm{U} / \mathrm{mL})$ added, lucigenin-enhanced chemiluminescence, $(10 \mu \mathrm{M})$, (f) with catalase $(44 \mathrm{nM}, 27.5 \mathrm{U} / \mathrm{mL})$ added, lucigenin-enhanced chemiluminescence, $(20 \mu \mathrm{M})$; concentrations of $\mathrm{Gd}_{0} \mathrm{C}_{82}$ are given in plots, phosphate buffer solution (100 mM pH 7.4); the total volume, $1000 \mathrm{~mL}$; temperature, $37^{\circ} \mathrm{C}$.

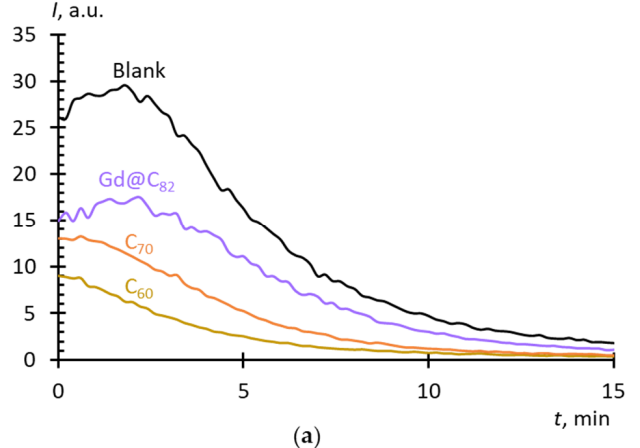

(a)

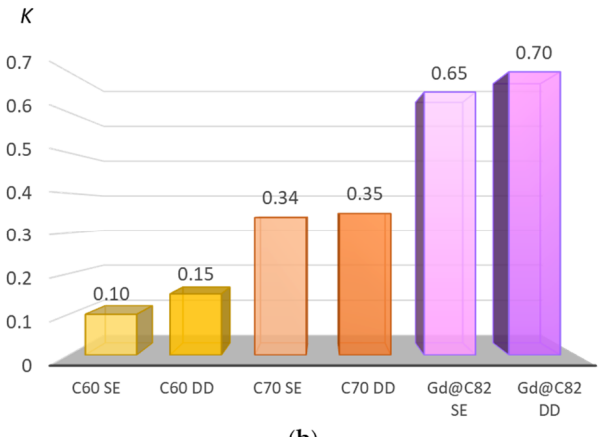

(b)

Figure 7. (a) Chemiluminograms of aqueous dispersions of fullerenes (17 $\mu \mathrm{M}$, direct dispergation) in a Krebs-Ringer solution + human fibroblasts $\left(1.0 \times 10^{6}\right.$ cells in $\left.\mathrm{mL}\right)+$ lucigenin $(0.4 \mathrm{mM})+\mathrm{NADH}$ $(0.8 \mathrm{mM})$; (b) Suppression constants $K=S / S_{0}$ for AFDs; SE is solvent replacement, DD is direct dispergation; the total volume, $1000 \mathrm{~mL}$; temperature, $37^{\circ} \mathrm{C}$. 


\section{Discussion}

Thus, the results obtained can be summed up as follows.

1. The AFDs prepared by solvent replacement have a slightly higher antioxidant activity than those prepared by direct dispersion.

2. With both methods of AFD preparation, fullerenes can be arranged in the row Gd@ $C_{82}>C_{60}>C_{70}$ with respect to the ability to scavenge $S A R$; and $C_{60}$ and $C_{70}$ differ in the mechanism of interaction with SAR from SOD, which allows them to be rather considered superoxide scavengers, in contrast to Gd@C 82 , which, presumably, is a SOD mimic.

3. With respect to the intracellular $S A R$, the activity of fullerenes decreases in the row $C_{60}>C_{70}>G d_{0} @ C_{82}$.

This requires considering all the factors that may affect the reactivity of fullerenes.

\subsection{Preparation Procedure}

As AFDs consist of fullerene clusters of ca. $100 \mathrm{~nm}$ in diameter (Table 1), not the whole molecular fullerene concentration should be taken into account. In fact, a more correct treatment of the concentration parameters is the cluster concentration or the concentration of fullerene molecules at the surface, an acting part of the fullerenes should be considered (Table 1).

The influence of the preparation method can be explained by the size of the obtained particles, the direct dispersion method is reported to result in larger particles [46]. The average cluster size for AFD $_{60}$ prepared by solvent-replacement was $277 \mathrm{~nm}$, for direct dispergation, $357 \mathrm{~nm}$ [47]. In this study, even after filtering through a $220 \mathrm{~nm}$ filter, the average particle size in the direct dispergation AFD was larger than the particle size obtained by solvent replacement (Table 1). A suspension of larger nanoparticles would provide a smaller total surface area for interaction and provide less reactive sites for ROS, thus reducing the efficiency of scavenging reactive species. The influence of the shape of fullerene molecules and their symmetry on the nature of cluster formation in AFD was discussed using the examples of $C_{60}$ and $C_{70}$ [48]. $C_{70}$ is characterized by the formation of larger clusters. The primary factor in the aggregation and, apparently, the nature of the formed cluster of molecules can be the dielectric constant $(\varepsilon)$ of solvent molecules, so for the aggregation of $C_{70}$ it was shown that $\varepsilon=27 \div 31$ are needed, for the aggregation of $\mathrm{C}_{60}$ the required range of $\varepsilon=12 \div 14$. Here, we observed identical values of the sizes of colloidal fullerene particles, and comparable absolute values of electrokinetic potentials.

Another explanation for differences in antioxidant activity of fullerenes may be the sorption of benzoic acid on the cluster surface at the process of solvent replacement. Toluene is dispersed in this process, and due to the oxidizing atmosphere, high ultrasound power, and water sonolysis [49] with the formation of the $\mathrm{OH}$. radical, toluene is oxidized to benzoic acid [50]. Benzoic acid itself has a pronounced antimicrobial effect [51], and its hydroxylated derivatives (2-hydroxybenzoic acid, etc.,) have an antioxidant effect beyond the phenol-like structure [52]. However, the complete elucidation of the composition of such impurity components was beyond the scope of this work.

Finally, when using the solvent replacement technique, even after cleaning, a solvent may remain in the system, which helps to form clusters with solvent molecules included [53,54]. Solvent molecules form a film-like solvate structures with water and/or toluene. In the case of the solvent replacement procedure, clusters with a nanoporous structure $(\sim 120 \mathrm{~nm})$ can form $[46,54]$, which are formed in toluene and then diffuse into the aqueous phase. Previously, we showed [55] that porous structures are characteristic for $\mathrm{C}_{60}$ and $\mathrm{C}_{70}$ clusters in AFDs by solvent replacement and can be isolated as solids. Presumably, the formed pores in fullerene clusters can serve as additional sites that increase the reactivity of fullerenes. There is data on the concentration dependence of AFD, the cluster sizes of which decrease with dilution [54]; however, we did not observe similar behavior for $C_{60}, C_{70}$, and Gd@C 82 . 


\subsection{Chemiluminescence System Based on Xanthine/Xanthine Oxidase}

It is interesting that the catalase addition to the $\mathrm{Xa} / \mathrm{XO}+$ luminol system increased the $\mathrm{CL}$ intensity (Figure 2a), which indicates the formation of extra ROS. This compound is unlikely to be singlet oxygen [56], but rather a hydroxyl radical formed by the Haber-Weiss reaction in the interaction of superoxide and hydrogen peroxide [57-60] or by the Fenton reaction with iron present in catalase samples [61]. It is possible that Fe(III) is formed during the oxidative degradation of catalase, as described in the study of the interaction of tert-butyl hydroperoxide with catalase [62]. There is evidence that SAR itself can have a damaging effect on catalase [63]. The confirmation of this hypothesis is in the study [64], where a sharp increase in lipid peroxidation by xanthine oxidase is observed upon adding catalase to the system, and this effect was inhibited by not only SOD, but iron chelators as well. The authors believe that the reduction of Fe(III) with superoxide to Fe(II) served as an effective trigger for lipid peroxidation.

Another possible explanation is the side peroxidase effect of catalase described in a few studies [65] when catalase catalyzes the oxidation of organic substrates in the presence of hydrogen peroxide. The "hydroxyl radical generation theory" was also proposed, according to which mammalian catalases generate hydroxyl radicals apart from their main catalytic reaction [66,67]. This effect depends on the concentration of hydrogen peroxide. At low concentrations of hydrogen peroxide, it is possible that the reaction mechanism switches, and ROS are formed instead of water and oxygen. However, such a prooxidant effect of catalase in the $\mathrm{Xa} / \mathrm{XO}+$ luminol system was not shown [68], the authors observed the expected decrease in CL. Such a difference with our results may be related to the reagent ratios. At approximately the same concentration of luminol $(20 \mu \mathrm{m}$ in this study and $25 \mu \mathrm{m}$ in [65], 1:1.25), we used 5-10-fold lower xanthine concentrations (10 $\mu \mathrm{m}$ compared to 50-500 $\mu \mathrm{m}$ ) and 18-fold lower xanthine oxidase activity $(2.2 \mathrm{U} / \mathrm{mL}$ compared to $40 \mathrm{U} / \mathrm{mL})$.

In our blank experiments for luminol $(20 \mathrm{mM})+$ hydrogen peroxide $(20 \mathrm{mM})+$ catalase $(44 \mathrm{nM}$, $27.5 \mathrm{U} / \mathrm{mL}$ ), an expected decrease in the CL signal was observed (the data not shown), which is consistent with the published data [69], but the interpretation of the catalase effect in a complex system for the generation of hydrogen peroxide by xanthine in the presence of xanthine oxidase requires further studies.

The addition of catalase to the $\mathrm{Xa} / \mathrm{XO}+$ lucigenin system led to the suppression of luminescence, which either indicates the presence of $\mathrm{H}_{2} \mathrm{O}_{2}$, to which lucigenin is also sensitive [70], or can be explained by the reaction of Fe(III) with SAR. It is highly likely that the effect of catalase on both luminol-dependent and lucigenin-dependent $\mathrm{CL}$ is due to the formed iron.

Thus, despite the widespread use of the $\mathrm{Xa} / \mathrm{XO}$ as a model, its reaction mechanism is extremely complex, which does not make it possible to simulate the kinetics and thus suggest a reaction scheme. Hence, we limited ourselves to comparing the properties of AFDs toward SAR relative to SOD as quantitative estimates and hypotheses on the mechanism of action; the proof of the latter may be a goal of separate studies involving other methods.

\subsection{Activity Mechanisms}

The study of the antioxidant properties of fullerenes is given special attention, since it is believed that they determine cytotoxicity, and non-functionalized fullerenes are more toxic to cells because of their lower antioxidant properties. The molecular mechanisms behind the antioxidant reactions of fullerenes with SAR remain controversial. Previously, the direct reaction between radical species and the highly conjugated double bond system of $\mathrm{C}_{60}$ was considered as the main mechanism. The authors [71] even referred to $\mathrm{C}_{60}$ as a free-radical "sponge" because the large polarizability of fullerenes [72] enables to attach radicals. Fullerenes show this row of electron affinity: $\mathrm{C}_{60}<\mathrm{C}_{70}<\mathrm{Gd} @ \mathrm{C}_{82}$; the values are 2.683(8), 2.765(10), and 3.3(1), respectively [73].

Figure $4 \mathrm{a}$, c show that $\mathrm{C}_{60}$ acts differently than SOD, as the plateau in this case reaches the blank level (compare with Figure 1a). Presumably, this means that substances that inhibits xanthine oxidase and hydrogen peroxide do not form. It could be assumed that $\mathrm{C}_{60}$ neutralizes hydrogen peroxide; however, our experiments in the CL system of hydrogen peroxide and luminol showed that $\mathrm{C}_{60}$ is inert 
with respect to peroxide or exhibits very weak peroxidase properties (data not shown). We also did not find any previous evidence of the catalase-like properties of pristine fullerenes. Therefore, it can be assumed that these differences are associated exactly with the different mechanism of reactions of SOD and $\mathrm{C}_{60}$ with superoxide. Probably, in this case, $\mathrm{C}_{60}$ should be considered not as a SOD mimic acting according to the catalytic mechanism, but rather a superoxide scavenger. Finally, Figure $4 \mathrm{e}$ reveals that $\mathrm{C}_{60}$ inhibits a luminol-dependent $\mathrm{CL}$, probably because of a decrease in SAR concentration, and its reaction with superoxide is faster than the reaction of superoxide with luminol. Noteworthy is that catalase in the presence of $\mathrm{C}_{60}$ does not exhibit a pro-oxidant effect. It can be assumed that $\mathrm{C}_{60}$, because of its antioxidant properties and rapid reaction kinetics, protects catalase from damage by SAR.

From Figure 1, Figure 4, and Figure 5 it follows that, most likely, the mechanism of interaction with superoxide for $\mathrm{C}_{60}$ and $\mathrm{C}_{70}$ is similar, and differences in activity are associated with the electron density in these molecules.

The comparison of Figure $1 \mathrm{a}$ and Fiugre $6 \mathrm{a}, \mathrm{c}$ shows that the mechanism of the reaction of Gd@ $\mathrm{C}_{82}$ with SAR is similar to the mechanism of SOD action and different from two other fullerenes. In both cases, in the presence of an antioxidant, the luminescence ends earlier, and its termination is characterized by a slope depending on the antioxidant concentration. However, Gd@C 82 does not protect catalase from oxidative damage: the level of luminol-dependent CL in Figure 6e is the same for catalase and catalase + Gd@ $\mathrm{C}_{82}$ cases. Perhaps this is due to a lower reaction rate of $\mathrm{Gd} @ \mathrm{C}_{82}$.

Presumably, the superoxide anion reacts with $\mathrm{Gd@C_{82 }}$ through a catalytic mechanism. This hypothesis is implicitly supported by the unchanged absorption and fluorescence spectra of $\mathrm{Gd} @ \mathrm{C}_{82}$ AFD in the course of the reaction with superoxide (the data not shown). To correctly substantiate this hypothesis, it is necessary either to carry out mathematical modeling, which, as discussed above, is not possible because of the complexity of the reaction mechanism in the $\mathrm{Xa} / \mathrm{XO}+$ lucigenin system, or, along with determining the concentration of SAR from lucigenin CL, to determine the amount of hydrogen peroxide formed as a result of dismutation. This cannot be quantified using peroxidase, since xanthine inhibits this enzyme [74], or by spectrophotometry because of the interfering effect of endofullerene. A way out could be the use of an electrochemical generation of a superoxide anion radical [75]. Therefore, we consider that the results obtained should be developed in further studies.

Much more studies have been devoted to fullerene derivatives, which consider being more efficient antioxidants in contrast to pristine fullerenes. For example, tris-malonic acid derivatives (C3) could remove the superoxide radical approximately 100-fold slower than SOD that was comparable to the range of values reported for several manganese-containing SOD mimic compounds, and C3 acted through the catalytic dismutation of superoxide [18,76,77]. Antioxidant properties of carboxyfullerenes depended on charge, size, shape, and hydrophobicity [78] as well as on the dipole moment [79]. The SOD activity of different carboxyfullerenes was also dependent on their reduction potentials; the higher the reduction potential, the higher the SOD dismutation activity [80]. Another example is hydrophilic carbon clusters that are oxidized carbon nanoparticles with a high affinity for electrons, which react with superoxide through a two-electron process with the formation of $\mathrm{H}_{2} \mathrm{O}_{2}$ as well as poly(ethylene glycolated) hydrophilic carbon clusters [81,82]. The authors used chemiluminescence techniques to prove that nanoparticles of fullerenols $\mathrm{Gd} @ \mathrm{C}_{82}(\mathrm{OH})_{22}$ and $\mathrm{C}_{60}(\mathrm{OH})_{22}$, as well as malonate-adduct $\mathrm{C}_{60}\left(\mathrm{C}(\mathrm{COOH})_{2}\right)_{2}$ were more efficient scavengers of SARs than water-soluble underivatized $\mathrm{C}_{60}$ [22]. They paid special attention that the derivatization of the fullerene cage with carboxyl and hydroxyl groups resulted in a drastic decrease in the ROS-induced cytotoxicity. They also demonstrated that Gd-endohedral fullerenes were much stronger ROS scavenger than hollow fullerenes [22].

Our results are consistent with this: $\mathrm{Gd} @ \mathrm{C}_{82}$ turned out to be an order of magnitude more effective antioxidant against superoxide than $C_{60}$ and $C_{70}$. The radical-scavenging abilities of fullerenes may be attributed to significant electron affinity: $2.7 \mathrm{eV}$ for $\mathrm{C}_{60}$ and $3.14 \mathrm{eV}$ for $\mathrm{C}_{82}$ [83,84]. The insertion of $\mathrm{Gd}$ into a $\mathrm{C}_{82}$ cage increases the electron affinity to $3.3 \mathrm{eV}$ [84]. Moreover, large polarizability of fullerenes facilitates the attachment of radicals to their surface [85]. Differences in electron affinities may contribute to the relative scavenging efficiencies $\mathrm{Gd} @ \mathrm{C}_{82}>\mathrm{C}_{60}$ and $\mathrm{C}_{70}$. 
The catalytic activity of endofullerenes can be accounted for by the asymmetric position of the endohedral Gd with respect to the carbon skeleton, and at least two carbon atoms of fullerene are more strongly bound to the endohedral atom by non-covalent interactions. According to [86], the electrons of the cage are bound more strongly because of their electrostatic interaction with the endohedral atom, which facilitates making $\mathrm{Gd} @ \mathrm{C}_{82}$ a stronger electron acceptor [86]. More negative redox potentials by cyclic voltammetry [86-88] indicate that endohedral metal fullerenes have a better reduction ability compared to $\mathrm{C}_{60}$ or $\mathrm{C}_{70}$, which is indirectly confirmed by electron affinity energies.

In addition, the introduction of a metal atom or other entity into the fullerene cage leads to the appearance of "extra" electrons in the $\pi$-electronic subsystem, the number of which depends on the valency or charge state of the embedded entity [89,90]. This explains the different behavior of endofullerenes compared to non-endohedral fullerenes. The most stable configuration for $\mathrm{Gd}_{\mathrm{d}} @ \mathrm{C}_{82}$ is when the gadolinium atom is adjacent to the double bond of the carbon skeleton (the mechanism of the in-plane inter-Gd@ $\mathrm{C}_{82}$ interaction on the electronic features, which would be helpful for qualitatively addressing the origin of the scanning tunneling spectroscopy states) [91].

\subsection{Intracellular SAR-Scavenging Activity}

With respect to intracellular superoxide, fullerenes can be arranged in a row $\mathrm{C}_{60}>\mathrm{C}_{70}>\mathrm{Gd} @ \mathrm{C}_{82}$, and $\mathrm{C}_{60}(K=0.15)$ was a $2-3$-fold more efficient intracellular superoxide scavenger than $\mathrm{C}_{70}(K=0.35)$ (Figure 7b). This is consistent with the $\mathrm{Xa} / \mathrm{XO}$ molecular model. However, the scavenging potential of $\mathrm{Gd} @ \mathrm{C}_{82}(K=0.62)$ was two-fold lower than that of $\mathrm{C}_{70}$ and five times lower than $\mathrm{C}_{60}$. Thus, unlike the molecular model, Gd@ $\mathrm{C}_{82}$ turned out to be the weakest antioxidant, which can be accounted for by a larger nanoparticle size. However, when evaluating intracellular activity, the permeability of substances through the membrane should be taken into account. Thus, such a row can be explained by higher lipid solubility (high hydrophobicity) that leads to accumulation in the cell membrane in the initial period of incubation. Here, the incubation time was $15 \mathrm{~min}$ that was enough for permeation of $\mathrm{C}_{60}$ and $\mathrm{C}_{70}$ into the cells but not for Gd@ $\mathrm{C}_{82}$. In the future, it is necessary to study the dynamics of the effect and vary the incubation time, but here it is clear that $\mathrm{Gd} @ \mathrm{C}_{82}$ will exhibit antioxidant properties with respect to the intracellular SAR.

In the case of unmodified fullerenes (especially for endofullerenes) there is no existing data on the strength of hydrophobic interactions. However, some conclusions may be made by the comparison of modified fullerenes. First, it was found that negatively charged $\mathrm{C}_{60}$ aggregates accumulate on deposited lipid bilayers consisting of cationic lipid head groups to a greater extent than on bilayers consisting of only zwitterionic lipid head groups under the same conditions [92]. Thus, it may be concluded that fullerene clusters interacted only with lipid head groups and did not penetrate lipid hydrocarbon chains. Also, the penetration time of $C_{70}-\gamma$-cyclodextrin from AFD into the membrane for HeLa cells is ca. $10 \mathrm{~min}$, whereas it was almost not observed for more stable $\mathrm{C}_{60}-\gamma$-cyclodextrin complex [93]. As well, permeability constants for AFDs at $\mathrm{pH} 7.4$ in a model biological membrane (L/mg $\times \mathrm{kg}$ lipid), are 3.30 for $\mathrm{C}_{60}$ and 3.08 for $\mathrm{C}_{60}(\mathrm{OH})_{24}$ [94]. These values suggest that the more hydrophilic fullerenol is less bound because of the electrostatic repulsion forces. A stronger hydrophobic and electrostatic interaction promotes more stable adsorption of $\mathrm{Gd} @ \mathrm{C}_{82}(\mathrm{OH})_{22}$ compared to other fullerenes [95]. $\mathrm{Gd} @ \mathrm{C}_{82}(\mathrm{OH})_{22}$ is relatively more hydrophobic compared to $\mathrm{C}_{60}(\mathrm{OH})_{24}$ because of the larger number of carbon atoms and fewer hydroxyl groups [95]. Meanwhile, the negatively charged endofullerene framework $\mathrm{Gd} @ \mathrm{C}_{82}$ because of electron transfer from the central atom [89] promotes electrostatic interaction with collagen, especially at the N-terminal nitrogen atom.

Thus, our data provide the basis for in-depth studies on cell models with a focus on studying the permeation and distribution of these substances and their intracellular antioxidant activity. 


\section{Materials and Methods}

\subsection{Chemicals}

Pristine $\mathrm{C}_{60}$ and $\mathrm{C}_{70}(>99.5 \%)$ fullerenes were purchased from Limited Liability Scientific and Production Company NeoTechProduct (St. Petersburg, Russia). The soot containing the Gd@ $\mathrm{C}_{2 \mathrm{n}}$ endohedral metal fullerenes (total content of $\mathrm{Gd}$ atoms up to $4 \mathrm{wt}$ \% checked by ICP-AES, and the value of total $\mathrm{Gd}$ was recalculated to the general formula of the molecule, $\mathrm{Gd} @ \mathrm{C}_{82}$ ) has been synthesized by the evaporation of the composite graphite electrodes compounded by gadolinium in the electric arc reactor as we previously described elsewhere [96]. Standard reference materials and quality control standards of required elements with certified values (Inorganic Ventures ${ }^{\mathrm{TM}}$, Christiansburg, VA, USA) were used to conduct ICP-AES measurements. A 20 ppm (in 5 wt. \% $\mathrm{HNO}_{3}$ ) scandium solution was used as an internal standard. Ultrapure water Milli-Q®Type (Merck, Darmstadt, Germany) was applied during the research (TOC $<3 \mathrm{ppb})$.

Phosphate buffer solutions (PBS) with $100 \mathrm{mM}$ and $\mathrm{pH} 7.4$ and 8.6 were prepared by dissolving a weighed portion of $\mathrm{KH}_{2} \mathrm{PO}_{4}$ (Sigma-Aldrich, St. Louis, MO, USA) in $1000 \mathrm{~L}$ of ultrapure water, followed by adjusting to the desired $\mathrm{pH}$ value using granular $\mathrm{KOH}$ (Sigma-Aldrich, USA). Solutions of xanthine (3,7-dihydropurine-2,6-dione, Sigma-Aldrich, USA) and a selective superoxide anion-radical of a chemiluminescent probe, lucigenin (10-methyl-9-(10-methylacridin-10-ium-9-yl)acridin-10-ium dinitrate, Sigma-Aldrich, USA), with working concentrations of $1 \mathrm{mM}$, was prepared by dissolving weighed portions in PBS with pHs of 8.6 and 7.4, respectively. A xanthine oxidase working solution (Sigma-Aldrich, USA, X1875-25UN) with an activity of $0.11 \mathrm{U} / \mathrm{mL}$ was obtained by diluting the initial PBS suspension ( $\mathrm{pH} 7.4$ ). Before luminescence measurements, the working solution of the enzyme was kept for $15 \mathrm{~min}$ at laboratory temperature. The catalytic activity of the one enzyme unit converts $1.0 \mu \mathrm{mol}$ of xanthine to uric acid in $1 \mathrm{~min}$ at $25^{\circ} \mathrm{C}$ and $\mathrm{pH} 7.5$. A stock solution of NADH (10 mM) (Sigma-Aldrich, USA) was prepared by dissolving a weighed portion of the substance in distilled water. Catalase from bovine liver, 2000-5000 U/mg protein was purchased from Sigma-Aldrich. A weighed portion of $0.0011 \mathrm{~g}$ was dissolved in $1000 \mathrm{~mL}$ of distilled water that corresponds to a $2750 \mathrm{U} / \mathrm{mL}$ activity. A $44 \mathrm{nM}$ solution of catalase corresponds to $27.5 \mathrm{U} / \mathrm{mL}$ final activity.

\subsection{Sample Preparation and Characterization}

AFDs was prepared by direct or solvent-replacement methods with a commercially available off-the-shelf ultrasound probe with a timer MEF93.T (LLC MELFIZ-ul'trazvuk, Moscow, Russia). Ultrasonic tip (surface areas $0.63 \pm 0.02 \mathrm{~cm}^{2}$ ) and electrical-power mode $(0.6 \mathrm{~kW})$ were used. Ultrasound tips were made of titanium alloys, grade TM3 (ISO 28401:2010).

\subsubsection{Preparation of Aqueous Fullerene Dispersions by Direct Ultrasound Probe Sonication}

The weighted fullerene portion of ca. $0.05 \mathrm{~g}, 10 \mathrm{~mL}$ of toluene, and $50 \mathrm{~mL}$ of ultrapure water were subsequently added to a conical flask $(250 \mathrm{~mL})$. The solution was exposed to ultrasonic treatment for $12 \mathrm{~h}$ with every $60 \mathrm{~min}$ pause for $30 \mathrm{~min}$. The prepared solution was filtered through a $0.45 \mu \mathrm{m}$ cellulose filter and diluted to the mark with $50 \mathrm{~mL}$ of ultrapure water.

\subsubsection{Preparation of Aqueous Fullerene Dispersions by Solvent-Replacement Ultrasound Probe Sonication}

The weighted fullerene portion of ca. $0.05 \mathrm{~g}, 10 \mathrm{~mL}$ of neat toluene, and $50 \mathrm{~mL}$ of ultrapure water were subsequently added to a conical flask $(250 \mathrm{~mL})$. The solution was exposed to ultrasonic treatment for $12 \mathrm{~h}$ with every $60 \mathrm{~min}$ pause for $30 \mathrm{~min}$. The prepared solution was filtered through a $0.45 \mu \mathrm{m}$ cellulose filter and diluted to the mark with $50 \mathrm{~mL}$ of ultrapure water. StrataX solid-phase extraction cartridges (Phenomenex, Torrance, CA, USA) were used for purified dispersion and eliminate organic compounds. 


\subsubsection{Characterization}

The colloidal characteristics of aqueous fullerene dispersions (particle size distribution and $\zeta$-potential) were determined by dynamic light scattering using a ZetaSizer Nano ZS (Malvern PANalytical, Malvern, UK) operating at $25^{\circ} \mathrm{C}$, the angle of backscattering $173^{\circ}$ according to ISO 22412:2017. An Agilent 720 ICP-OES spectrometer (Agilent Technologies Inc., Santa Clara, CA, USA) with an axial view was used for elemental analysis.

\subsection{Chemiluminescence Experiments}

A 12-channel Lum-1200 chemiluminometer (DISoft, Moscow, Russia) was used for chemiluminometry measurements. The chemiluminometer provides the detection of visible light within a range from 300 to $700 \mathrm{~nm}$. No light filters were used in our experiments. Signal processing and data handling were performed with PowerGraph 3.3 Professional software (DISoft, Moscow, Russia).

\subsubsection{Chemiluminescence Analysis of Superoxide Scavenging Potential}

Superoxide scavenging potential was assessed by chemiluminometry with the $\mathrm{Xa} / \mathrm{XO}$ model system in the presence of lucigenin as a selective enhancer for SAR. Aliquots of xanthine $(25 \mu \mathrm{M})$, lucigenin $(25 \mu \mathrm{M})$, and the analyzed sample were added to a cuvette with the PBS (100 mM, $\mathrm{pH}$ 7.4). The background luminescence was recorded for 30-60 s, then an aliquot of xanthine oxidase $(a=5.5 \mathrm{mU} / \mathrm{mL})$ was added. The total volume of the system was $1000 \mathrm{~mL}$. The samples were analyzed in triplicates. As an analytical signal, the ratio of the of the stationary intensity to the intensity of the control experiment $I / I_{0}$ was used. Experiments were performed at $37^{\circ} \mathrm{C}$.

To confirm that AFDs did not inhibit xanthine oxidase activity, we measured both uric acid and $\mathrm{O}_{2}$ consumption during the reaction. Oxygen content was assessed using a Clark type electrode DTKP-02 (Ekoniks-Ekspert, Moscow, Russia). Uric acid was determined electrochemically [97]. The formation of uric acid, i.e., xanthine oxidase activity, was not inhibited by any AFDs (data not shown).

\subsubsection{NADH-Stimulated Lucigenin-Enhanced Chemiluminescence of Human Fibroblasts}

Human fetal lung fibroblasts (the fourth cell passage) were provided by the Research Centre for Medical Genetics. Cells were seeded at $17 \times 10^{4}$ per $\mathrm{mL}$ in DMEM (Dulbecco's Modified Eagle Medium) (Paneco, Moscow, Russia) with 10\% fetal calf serum (PAA, Vienna, Austria), 50 U/mL penicillin, $50 \mu \mathrm{g} / \mathrm{mL}$ streptomycin, and $10 \mu \mathrm{g} / \mathrm{mL}$ gentamycin, and cultured at $37^{\circ} \mathrm{C}$ for $24 \mathrm{~h}$. After adding the fullerenes to the medium, the cells were incubated for $15 \mathrm{~min}$.

The cells were placed into a cuvette with Krebs-Ringer buffer solution and lucigenin $(0.4 \mathrm{mM})$. Chemiluminescence was recorded at $37^{\circ} \mathrm{C}$ for $2 \mathrm{~min}$, then NADH solution were added $(0.8 \mathrm{mM})$ and the chemiluminescence was recorded for $15 \mathrm{~min}$. From the chemiluminograms, the area under the curve for $20 \mathrm{~min}$ was determined, and the suppression of luminescence relative to blank was calculated $\left(K=S / S_{0}\right)$.

\subsection{Cluster Parameters in Aqueous Fullerene Dispersions}

We assumed a spherical structure of the clusters and the fact that fullerenes form a face-centered cubic lattice. The outer average diameter of the molecules: for $C_{60} 6.5 \AA$, [98] for the c-axis $C_{70}$ $7.96 \AA$ [99] (values 7.12 $\AA$ along the a and b-axes were not used), and Gd@C 82 14.30 [100]. The cluster concentration of fullerenes in AFD ć (Table 1) was calculated as: $\dot{c}=(1 / k)(d / D)^{3}\left(c N_{\mathrm{A}} / 1000 M\right)$, where $D$ is the average diameter of the fullerene cluster, $\mathrm{nm}, d$ is the diameter of the fullerene molecule $\mathrm{C}_{60}, \mathrm{C}_{70}$, or $\mathrm{Gd} @ \mathrm{C}_{82}, \mathrm{~nm}, c$; is the $w / v$ concentration of fullerene in the sample $(\mathrm{mg} / \mathrm{L}), N_{A}$ is Avogadro's number, $M$ is the molar mass of the fullerene $(\mathrm{g} / \mathrm{mol})$, and $k$ is the packing coefficient of the face-centered cubic lattice of 0.7404 . We also estimated: $(i)$ The number of molecules in one cluster $n_{\mathrm{c}}=(D / d)^{3} k$; (ii) the number of molecules on the surface of the cluster, taking into account that only a half of the surface of the molecule works, and the rest is inside the cluster by the formula $n_{\mathrm{c} \text { surf }}=2(D / d)^{2}$; (iii) the fraction of 
active (surface) fullerenes in cluster is the ratio of the number of molecules on the surface of the cluster to their total number in the cluster (fraction of the working surface of the cluster) as $\eta=n_{\mathrm{c} / \mathrm{surf}} / n_{\mathrm{c}} \times 100 \%$; and (iv) acting (surface) fullerene concentration as $c^{\prime}$, act $=\dot{c} /\left(N_{A} n_{\mathrm{c} \text { surf }}\right)$. The calculated parameters are summed up in Table 1.

\section{Conclusions}

Based on the results of studying SOD scavenging activity, the following conclusions can be made: (1) $C_{60}$ and $C_{70}$ aqueous dispersions react with superoxide as scavengers by a similar mechanism, differences in their activity are determined by cluster parameters, primarily the concentration of active (acting) molecules at the surface; (2) Gd endofullerene is characterized by a significantly (one and a half to two orders of magnitude) higher reactivity compared to non-endohedral fullerenes and is likely to exhibit SOD-mimic catalytic properties, which can be explained by the nonuniform distribution of electron density of the fullerene cage due to the presence of an endohedral atom; (3) slightly higher antioxidant activity of aqueous fullerene dispersions by the method of solvent replacement is most likely due to the effect of benzoic acid adsorbed at the fullerene clusters; (4) in the cell model, Gd endofullerene showed the lowest activity compared to $C_{60}$ and $C_{70}$, which may be accounted for by a higher affinity for the lipid phase preventing its appearance within the cell. Still, these studies may be considered as a proof-of-concept. The continuation of these studies may be helpful in: (1) studying antioxidant potentialities of aqueous fullerene dispersions in relation to other biochemical reference systems (lipoperoxidases or phospholipoperoxidases), including computer-based simulation of the kinetics mechanism and (2) studying fullerenes in aqueous dispersions as regulators of cellular ROS homeostasis, for example, cytotoxicity, permeation into cells and their distribution, and visualization of intracellular ROS in the presence of fullerenes. Also, it could be mentioned that the shown ability of Gd endofullerenes as intracellular superoxide scavengers would make them promising cytoprotective MRI contrasting agents.

Supplementary Materials: The following are available online, Figures S1-S2: UV/vis spectra of different types of aqueous dispersions (filtered and not-filtered); Figures S3-S4: FTIR-ATR spectra of the pristine fullerenes and their aqueous dispersions.

Author Contributions: Conceptualization, E.V.P. and M.A.P.; methodology, E.V.P. and M.A.P.; validation, I.V.M. and M.M.S.; investigation, I.V.M. and M.M.S.; resources and sample synthesis, I.E.K.; data curation, E.V.P. and M.A.P.; writing—original draft preparation, I.V.M., M.M.S., and E.V.P.; writing-review and editing, E.V.P. and M.A.P.; supervision, M.A.P.; project administration, M.A.P.; funding acquisition, I.V.M. All authors have read and agreed to the published version of the manuscript.

Funding: This research was funded by the Russian Science Foundation, Project No. 19-73-00143.

Acknowledgments: V.P. Bubnov, who provided the technical support for Gd-endofullerene synthesis.

Conflicts of Interest: The authors declare no conflict of interest.

\section{References}

1. Halliwell, B.; Gutteridge, J.M.C. Free Radicals in Biology and Medicine; Oxford University Press: Oxford, UK, 2015.

2. Sies, H. Oxidative Stress; Elsevier Science: London, UK, 2013.

3. Ray, P.D.; Huang, B.W.; Tsuji, Y. Reactive oxygen species (ROS) homeostasis and redox regulation in cellular signaling. Cell. Signal. 2012, 24, 981-990. [CrossRef] [PubMed]

4. Schieber, M.; Chandel, N.S. ROS function in redox signaling and oxidative stress. Curr. Biol. 2014, $24,453-462$. [CrossRef] [PubMed]

5. Sies, H.; Jones, D.P. Reactive oxygen species (ROS) as pleiotropic physiological signalling agents. Nat. Rev. Mol. Cell Biol. 2020, 1-21. [CrossRef] [PubMed]

6. McCord, J.M.; Edeas, M.A. SOD, oxidative stress and human pathologies: A brief history and a future vision. Biomed. Pharmacother. 2005, 59, 139-142. [CrossRef] 
7. Sheng, Y.; Abreu, I.A.; Cabelli, D.E.; Maroney, M.J.; Miller, A.F.; Teixeira, M.; Valentine, J.S. Superoxide dismutases and superoxide reductases. Chem Rev. 2014, 114, 3854-3918. [CrossRef]

8. Salvemini, D.; Muscoli, C.; Riley, D.P.; Cuzzocrea, S. Superoxide dismutase mimetics. Pulm. Pharmacol. Ther. 2002, 15, 439-447. [CrossRef]

9. Batinic-Haberle, I.; Tovmasyan, A.; Roberts, E.R.; Vujaskovic, Z.; Leong, K.W.; Spasojevic, I. SOD therapeutics: Latest insights into their structure-activity relationships and impact on the cellular redox-based signaling pathways. Antioxid. Redox Signal. 2014, 20, 2372-2415. [CrossRef]

10. Bonetta, R. Potential therapeutic applications of MnSODs and SOD-mimetics. Chemistry 2018, 24, 5032-5041. [CrossRef]

11. Wei, H.; Wang, E. Nanomaterials with enzyme-like characteristics (nanozymes): Next-generation artificial enzymes. Chem. Soc. Rev. 2013, 42, 6060-6093. [CrossRef]

12. Madkour, L.H. Antioxidants, Therapeutic Options, and Regulation of the Immune Responses. In Nanoparticles Induce Oxidative and Endoplasmic Reticulum Stresses; Springer International Publishing: Cham, Switzerland, 2020; pp. 631-665.

13. Wu, J.; Wang, X.; Wang, Q.; Lou, Z.; Li, S.; Zhu, Y.; Qin, L.; Wei, H. Nanomaterials with enzyme-like characteristics (nanozymes): Next-generation artificial enzymes (II). Chem. Soc. Rev. 2019, 48, 1004-1076. [CrossRef]

14. Yan, W.; Seifermann, S.M.; Pierrat, P.; Brase, S. Synthesis of highly functionalized C60 fullerene derivatives and their applications in material and life sciences. Org. Biomol. Chem. 2015, 13, 25-54. [CrossRef] [PubMed]

15. Dugan, L.L.; Turetsky, D.M.; Du, C.; Lobner, D.; Wheeler, M.; Almli, C.R.; Shen, C.K.; Luh, T.Y.; Choi, D.W.; Lin, T.S. Carboxyfullerenes as neuroprotective agents. Proc. Natl. Acad. Sci. USA 1997, 94, 9434-9439. [CrossRef] [PubMed]

16. Yan, X. Nanozymology: Connecting Biology and Nanotechnology. Springer: Singapore, 2020.

17. Li, R.; Zhen, M.; Guan, M.; Chen, D.; Zhang, G.; Ge, J.; Gong, P.; Wang, C.; Shu, C. A novel glucose colorimetric sensor based on intrinsic peroxidase-like activity of C60-carboxyfullerenes. Biosens Bioelectron 2013, 47, 502-507. [CrossRef] [PubMed]

18. Ali, S.S.; Hardt, J.I.; Quick, K.L.; Kim-Han, J.S.; Erlanger, B.F.; Huang, T.T.; Epstein, C.J.; Dugan, L.L. A biologically effective fullerene (C60) derivative with superoxide dismutase mimetic properties. Free Radic. Biol. Med. 2004, 37, 1191-1202. [CrossRef] [PubMed]

19. Nielsen, G.D.; Roursgaard, M.; Jensen, K.A.; Poulsen, S.S.; Larsen, S.T. In vivo biology and toxicology of fullerenes and their derivatives. Basic Clin. Pharmacol. Toxicol. 2008, 103, 197-208. [CrossRef]

20. Aschberger, K.; Johnston, H.J.; Stone, V.; Aitken, R.J.; Tran, C.L.; Hankin, S.M.; Peters, S.A.; Christensen, F.M. Review of fullerene toxicity and exposure-appraisal of a human health risk assessment, based on open literature. Regul. Toxicol. Pharmacol. Rtp 2010, 58, 455-473. [CrossRef]

21. Gharbi, N.; Pressac, M.; Hadchouel, M.; Szwarc, H.; Wilson, S.R.; Moussa, F. [60]fullerene is a powerful antioxidant in vivo with no acute or subacute toxicity. Nano. Lett. 2005, 5, 2578-2585. [CrossRef]

22. Yin, J.J.; Lao, F.; Fu, P.P.; Wamer, W.G.; Zhao, Y.; Wang, P.C.; Qiu, Y.; Sun, B.; Xing, G.; Dong, J.; et al. The scavenging of reactive oxygen species and the potential for cell protection by functionalized fullerene materials. Biomaterials 2009, 30, 611-621. [CrossRef]

23. Hudhomme, P.; O’Brien, P.; De La Puente, F.L.; Kroto, H.; Hiroshi, I.; Nierengarten, J.F.; Craighead, H.; Guldi, D.; Paolucci, F.; Burley, G. Fullerenes: Principles and Applications; Royal Society of Chemistry: Cambridge, UK, 2011.

24. Miyazawa, K.; Ochiai, Y.; Tachibana, M.; Kizuka, T.; Nakamura, S. Fullerene Nanowhiskers; Jenny Stanford Publishing: Singapore, 2019.

25. Jorio, A. Bioengineering Applications of Carbon Nanostructures; Springer International Publishing: Cham, Switzerland, 2015.

26. Lin, A.M.; Fang, S.F.; Lin, S.Z.; Chou, C.K.; Luh, T.Y.; Ho, L.T. Local carboxyfullerene protects cortical infarction in rat brain. Neurosci. Res. 2002, 43, 317-321. [CrossRef]

27. Hayyan, M.; Hashim, M.A.; AlNashef, I.M. Superoxide ion: Generation and chemical implications. Chem. Rev. 2016, 116, 3029-3085. [CrossRef]

28. Braun, K.; Dunsch, L.; Pipkorn, R.; Bock, M.; Baeuerle, T.; Yang, S.; Waldeck, W.; Wiessler, M. Gain of a 500-fold sensitivity on an intravital MR contrast agent based on an endohedral gadolinium-cluster-fullerene-conjugate: A new chance in cancer diagnostics. Int. J. Med. Sci. 2010, 7, 136-146. [CrossRef] 
29. Shinohara, H.; Tagmatarchis, N.; Kroto, H. Endohedral Metallofullerenes: Fullerenes with Metal Inside; Wiley: Hoboken, NJ, USA, 2015.

30. Chen, C.; Xing, G.; Wang, J.; Zhao, Y.; Li, B.; Tang, J.; Jia, G.; Wang, T.; Sun, J.; Xing, L.; et al. Multihydroxylated [Gd@C82(OH)22]n nanoparticles: Antineoplastic activity of high efficiency and low toxicity. Nano Lett. 2005, 5, 2050-2057. [CrossRef]

31. Ko, W.B.; Heo, J.Y.; Nam, J.H.; Lee, K.B. Synthesis of a water-soluble fullerene $\left[\mathrm{C}_{60}\right]$ under ultrasonication. Ultrasonics 2004, 41, 727-730. [CrossRef] [PubMed]

32. Mikheev, I.V.; Khimich, E.S.; Rebrikova, A.T.; Volkov, D.S.; Proskurnin, M.A.; Korobov, M.V. Quasi-equilibrium distribution of pristine fullerenes $C_{60}$ and $C_{70}$ in a water-toluene system. Carbon 2017, 111,191-197. [CrossRef]

33. Mikheev, I.V.; Kareev, I.E.; Bubnov, V.P.; Volkov, D.S.; Korobov, M.V.; Proskurnin, M.A. Aqueous dispersions of unmodified $Y @ C_{82}\left(C_{2 v}\right)$ endohedral metallofullerene. Chemistry Select. 2017, 2, 8936-8940. [CrossRef]

34. Sadana, A.; Ahuja, S. Bioseparations of Proteins: Unfolding/Folding and Validations; Elsevier Science: San Diego, CA, USA, 1997.

35. Taurozzi, J.S.; Hackley, V.A.; Wiesner, M. Preparation of nanoparticle dispersions from powdered material using ultrasonic disruption. Nist Spec. Publ. 2012, 1200, 1200-1202.

36. Storch, J.; Ferber, E. Detergent-amplified chemiluminescence of lucigenin for determination of superoxide anion production by NADPH oxidase and xanthine oxidase. Anal. Biochem 1988, 169, 262-267. [CrossRef]

37. Qi, J.; Sun, L.Q.; Qian, S.Y.; Yu, B.Y. A novel multi-hyphenated analytical method to simultaneously determine xanthine oxidase inhibitors and superoxide anion scavengers in natural products. Anal. Chim Acta 2017, 984, 124-133. [CrossRef]

38. Radi, R.; Tan, S.; Prodanov, E.; Evans, R.A.; Parks, D.A. Inhibition of xanthine oxidase by uric acid and its influence on superoxide radical production. Biochim Biophys Acta 1992, 1122, 178-182. [CrossRef]

39. Lynch, R.E.; Fridovich, I. Autoinactivation of xanthine oxidase: The role of superoxide radical and hydrogen peroxide. Biochim Biophys Acta 1979, 571, 195-200. [CrossRef]

40. Link, E.M.; Riley, P.A. Role of hydrogen peroxide in the cytotoxicity of the xanthine/xanthine oxidase system. Biochem J. 1988, 249, 391-399. [CrossRef] [PubMed]

41. Lacy, F.; Gough, D.A.; Schmid-Schonbein, G.W. Role of xanthine oxidase in hydrogen peroxide production. Free Radic. Biol. Med. 1998, 25, 720-727. [CrossRef]

42. Radi, R.A.; Rubbo, H.; Prodanov, E. Comparison of the effects of superoxide dismutase and cytochrome c on luminol chemiluminescence produced by xanthine oxidase-catalyzed reactions. Biochim. Biophys. Acta 1989, 994, 89-93. [CrossRef]

43. Bedouhene, S.; Moulti-Mati, F.; Hurtado-Nedelec, M.; Dang, P.M.; El-Benna, J. Luminol-amplified chemiluminescence detects mainly superoxide anion produced by human neutrophils. Am. J. Blood Res. 2017, 7, 41-48.

44. Baker, M.A.; Krutskikh, A.; Curry, B.J.; Hetherington, L.; Aitken, R.J. Identification of cytochrome-b5 reductase as the enzyme responsible for NADH-dependent lucigenin chemiluminescence in human spermatozoa. Biol. Reprod. 2005, 73, 334-342. [CrossRef]

45. Schepetkin, I.A. Lucigenin as a substrate of microsomal NAD(P)H-oxidoreductases. Biochemistry. Biokhimiia 1999, 64, 25-32. [PubMed]

46. Yang, S.; Mulet, X.; Gengenbach, T.; Waddington, L.; Seeber, A.; Zhen, M.; Wang, C.; Muir, B.W.; Such, G.K.; Hao, X. Limitations with solvent exchange methods for synthesis of colloidal fullerenes. Colloids and Surfaces A: Physicochemical and Engineering Aspects 2017, 514, 21-31. [CrossRef]

47. Brant, J.A.; Labille, J.; Bottero, J.Y.; Wiesner, M.R. Characterizing the impact of preparation method on fullerene cluster structure and chemistry. Langmuir 2006, 22, 3878-3885. [CrossRef]

48. Nath, S.; Pal, H.; Sapre, A.V. Effect of solvent polarity on the aggregation of fullerenes: A comparison between $\mathrm{C}_{60}$ and $\mathrm{C}_{70}$. Chem. Phys. Lett. 2002, 360, 422-428. [CrossRef]

49. Colmenares, J.C.; Chatel, G. Sonochemistry: From Basic Principles to Innovative Applications; Springer International Publishing: Cham, Switzerland, 2017.

50. Mikheev, I.V.; Pirogova, M.O.; Bolotnik, T.A.; Volkov, D.S.; Korobov, M.V.; Proskurnin, M.A. Optimization of the solvent-exchange process for high-yield synthesis of aqueous fullerene dispersions. Nanosyst. Phys. Chem. Math. 2018, 1, 41-45. [CrossRef] 
51. Kluge, H.; Broz, J.; Eder, K. Effect of benzoic acid on growth performance, nutrient digestibility, nitrogen balance, gastrointestinal microflora and parameters of microbial metabolism in piglets. J. Anim. Physiol. Anim. Nutr. (Berl.) 2006, 90, 316-324. [CrossRef] [PubMed]

52. Sen, C.; Packer, L.; Hänninen, O. Handbook of Oxidants and Antioxidants in Exercise; Elsevier Science: Amsterdam, Netherlands, 2000.

53. Deguchi, S.; Alargova, R.G.; Tsujii, K. stable dispersions of fullerenes, $C_{60}$ and $C_{70}$, in water. Preparation and characterization. Langmuir 2001, 17, 6013-6017. [CrossRef]

54. Avdeev, M.V.; Khokhryakov, A.A.; Tropin, T.V.; Andrievsky, G.V.; Klochkov, V.K.; Derevyanchenko, L.I.; Rosta, L.; Garamus, V.M.; Priezzhev, V.B.; Korobov, M.V.; et al. Structural features of molecular-colloidal solutions of $\mathrm{C}_{60}$ fullerenes in water by small-angle neutron scattering. Langmuir 2004, 20, 4363-4368. [CrossRef]

55. Mikheev, I.V.; Usoltseva, L.O.; Ivshukov, D.A.; Volkov, D.S.; Korobov, M.V.; Proskurnin, M.A. Approach to the assessment of size-dependent thermal properties of disperse solutions: Time-resolved photothermal lensing of aqueous pristine fullerenes C60 and C70. J. Phys. Chem. C 2016, 120, 28270-28287. [CrossRef]

56. Nagano, T.; Fridovich, I. Does the aerobic xanthine oxidase reaction generate singlet oxygen? Photochem. Photobiol. 1985, 41, 33-37. [CrossRef] [PubMed]

57. Beauchamp, C.; Fridovich, I. A mechanism for the production of ethylene from methional. The generation of the hydroxyl radical by xanthine oxidase. J. Biol. Chem. 1970, 245, 4641-4646.

58. Bannister, J.V.; Bannister, W.H.; Hill, H.A.; Thornalley, P.J. Enhanced production of hydroxyl radicals by the xanthine-xanthine oxidase reaction in the presence of lactoferrin. Biochim Biophys Acta 1982, 715, 116-120. [CrossRef]

59. Kuppusamy, P.; Zweier, J.L. Characterization of free radical generation by xanthine oxidase. Evidence for hydroxyl radical generation. J. Biol. Chem. 1989, 264, 9880-9884.

60. Mori, H.; Arai, T.; Mori, K.; Tsutsui, H.; Makino, K. Use of M4PO and oxygen-17 in the study on hydroxyl radical generation in the hypoxanthine-xanthine oxidase reaction. Biochem. Mol. Biol. Int. 1994, 32, 523-529.

61. Britigan, B.E.; Pou, S.; Rosen, G.M.; Lilleg, D.M.; Buettner, G.R. Hydroxyl radical is not a product of the reaction of xanthine oxidase and xanthine. The confounding problem of adventitious iron bound to xanthine oxidase. J. Biol. Chem. 1990, 265, 17533-17538.

62. Pichorner, H.; Jessner, G.; Ebermann, R. tBOOH acts as a suicide substrate for catalase. Arch. Biochem Biophys 1993, 300, 258-264. [CrossRef] [PubMed]

63. Kono, Y.; Fridovich, I. Superoxide radical inhibits catalase. J. Biol. Chem. 1982, 257, 5751-5754.

64. Miura, T.; Sakurai, K.; Ogiso, T. Enhanced lipid peroxidation of erythrocyte membranes and phosphatidylcholine liposomes induced by a xanthine oxidase system in the presence of catalase. Chem Pharm. Bull. (Tokyo) 1984, 32, 3227-3234. [CrossRef] [PubMed]

65. Artemchik, V.D.; Kurchenko, V.P.; Metelitsa, D.I. Peroxidase activity of catalase with respect to aromatic amines. Biokhimiia 1985, 50, 826-832. [PubMed]

66. Goyal, M.M.; Basak, A. Hydroxyl radical generation theory: A possible explanation of unexplained actions of mammalian catalase. Int. J. Biochem. Mol. Biol. 2012, 3, 282-289. [CrossRef] [PubMed]

67. Goyal, M.M. Hydroxyl radical generation by mammalian catalase: A few experimental evidences. Biochem. Pharmacol. Open Access 2012, 1, 1000103. [CrossRef]

68. Wilhelm, J.; Vilim, V. Variables in xanthine oxidase-initiated luminol chemiluminescence: Implications for chemiluminescence measurements in biological systems. Anal. Biochem. 1986, 158, 201-210. [CrossRef]

69. Rost, M.; Karge, E.; Klinger, W. What do we measure with luminol-, lucigenin- and penicillin-amplified chemiluminescence? 1. Investigations with hydrogen peroxide and sodium hypochlorite. J. Biolumin Chemilumin 1998, 13, 355-363. [CrossRef]

70. Riehl, T.E.; Malehorn, C.L.; Hinze, W.L. Characterisation and evaluation of the use of membrane mimetic agents to amplify chemiluminescence from the lucigenin-hydrogen peroxide reaction system. Analyst 1986, 111, 931-939. [CrossRef]

71. Krusic, P.J.; Wasserman, E.; Keizer, P.N.; Morton, J.R.; Preston, K.F. Radical reactions of C 60 . Science 1991, 254, 1183-1185. [CrossRef]

72. Zhou, Y.; Li, J.; Ma, H.; Zhen, M.; Guo, J.; Wang, L.; Jiang, L.; Shu, C.; Wang, C. Biocompatible [60]/[70] fullerenols: Potent defense against oxidative injury induced by reduplicative chemotherapy. Acs Appl. Mater. Interfaces 2017, 9, 35539-35547. [CrossRef] [PubMed] 
73. Popov, A.A. Endohedral Fullerenes: Electron. Transfer and Spin; Springer International Publishing: Cham, Switzerland, 2017.

74. Kimura, S.; Jellinck, P.H. Rat intestinal peroxidase: Inhibition by endogenous xanthine and xanthine oxidase. Arch. Biochem Biophys 1985, 241, 141-148. [CrossRef]

75. Matsuoka, M.; Jin, J. Application of electrochemiluminescence for the evaluation of the antioxidant capacity of some phenolic compounds against superoxide anion radicals. Anal. Sci 2015, 31, 629-634. [CrossRef] [PubMed]

76. Bensasson, R.V.; Brettreich, M.; Frederiksen, J.; Gottinger, H.; Hirsch, A.; Land, E.J.; Leach, S.; McGarvey, D.J.; Schonberger, H. Reactions of e(-)(aq), $\mathrm{CO}(2)\left(^{*}\right)(-), \mathrm{HO}\left({ }^{*}\right), \mathrm{O}(2)\left(^{*}\right)(-)$ and $\mathrm{O}(2)((1)$ delta(g)) with a dendro[60]fullerene and $\mathrm{C}(60)[\mathrm{C}(\mathrm{COOH})(2)](\mathrm{n})(\mathrm{n}=2-6)$. Free Radic. Biol. Med. 2000, 29, 26-33. [CrossRef]

77. Okuda, K.; Hirota, T.; Hirobe, M.; Nagano, T.; Mochizuki, M.; Mashino, T. Synthesis of various water-soluble G60 derivatives and their superoxide-quenching activity. Fuller. Sci. Technol. 2000, 8, 127-142. [CrossRef]

78. Witte, P.; Beuerle, F.; Hartnagel, U.; Lebovitz, R.; Savouchkina, A.; Sali, S.; Guldi, D.; Chronakis, N.; Hirsch, A. Water solubility, antioxidant activity and cytochrome $\mathrm{C}$ binding of four families of exohedral adducts of C60 and C70. Org. Biomol. Chem. 2007, 5, 3599-3613. [CrossRef]

79. Ali, S.S.; Hardt, J.I.; Dugan, L.L. SOD activity of carboxyfullerenes predicts their neuroprotective efficacy: A structure-activity study. Nanomedicine 2008, 4, 283-294. [CrossRef]

80. Liu, G.F.; Filipovic, M.; Ivanovic-Burmazovic, I.; Beuerle, F.; Witte, P.; Hirsch, A. High catalytic activity of dendritic $\mathrm{C}_{60}$ monoadducts in metal-free superoxide dismutation. Angew. Chem. 2008, 47, 3991-3994. [CrossRef]

81. Jalilov, A.S.; Zhang, C.; Samuel, E.L.; Sikkema, W.K.; Wu, G.; Berka, V.; Kent, T.A.; Tsai, A.L.; Tour, J.M. Mechanistic study of the conversion of superoxide to oxygen and hydrogen peroxide in carbon nanoparticles. Acs Appl. Mater. Interfaces 2016, 8, 15086-15092. [CrossRef]

82. Wu, G.; Berka, V.; Derry, P.J.; Mendoza, K.; Kakadiaris, E.; Roy, T.; Kent, T.A.; Tour, J.M.; Tsai, A.L. Critical comparison of the superoxide dismutase-like activity of carbon antioxidant nanozymes by direct superoxide consumption kinetic measurements. Acs Nano 2019, 13, 11203-11213. [CrossRef] [PubMed]

83. Wang, L.-S.; Conceicao, J.; Jin, C.; Smalley, R.E. Threshold photodetachment of cold C-60. Chem. Phys. Lett. 1991, 182, 5-11. [CrossRef]

84. Boltalina, O.V.; Ioffe, I.N.; Sorokin, I.D.; Sidorov, L.N. Electron affinity of some endohedral lanthanide fullerenes. J. Phys. Chem. A 1997, 101, 9561-9563. [CrossRef]

85. Ptasinska, S.; Echt, O.; Denifl, S.; Stano, M.; Sulzer, P.; Zappa, F.; Stamatovic, A.; Scheier, P.; Mark, T.D. Electron attachment to higher fullerenes and to Sc3N@C80. J. Phys. Chem. A 2006, 110, 8451-8456. [CrossRef] [PubMed]

86. Suzuki, T.; Kikuchi, K.; Oguri, F.; Nakao, Y.; Suzuki, S.; Achiba, Y.; Yamamoto, K.; Funasaka, H.; Takahashi, T. Electrochemical properties of fullerenolanthanides. Tetrahedron 1996, 52, 4973-4982. [CrossRef]

87. Haufler, R.E.; Conceicao, J.; Chibante, L.P.F.; Chai, Y.; Byrne, N.E.; Flanagan, S.; Haley, M.M.; O’Brien, S.C.; Pan, C. Efficient production of $\mathrm{C} 60$ (buckminsterfullerene), $\mathrm{C} 60 \mathrm{H} 36$, and the solvated buckide ion. J. Phys. Chem. 1990, 94, 8634-8636. [CrossRef]

88. Boudon, C.; Gisselbrecht, J.-P.; Gross, M.; Herrmann, A.; Rüttimann, M.; Crassous, J.; Cardullo, F.; Echegoyen, L.; Diederich, F. Redox characteristics of covalent derivatives of the higher fullerenes C70, C76, and C78. J. Am. Chem. Soc. 1998, 120, 7860-7868. [CrossRef]

89. Popov, A.A.; Yang, S.; Dunsch, L. Endohedral fullerenes. Chem Rev. 2013, 113, 5989-6113. [CrossRef]

90. Shinohara, H. Endohedral metallofullerenes. Rep. Prog. Phys. 2000, 63, 843-892. [CrossRef]

91. Senapati, L.; Schrier, J.; Whaley, K.B. Electronic transport, structure, and energetics of endohedral Gd@C82 metallofullerenes. Nano Lett. 2004, 4, 2073-2078. [CrossRef]

92. Spurlin, T.A.; Gewirth, A.A. Effect of C60 on solid supported lipid bilayers. Nano Lett. 2007, 7, 531-535. [CrossRef]

93. Ikeda, A.; Matsumoto, M.; Akiyama, M.; Kikuchi, J.; Ogawa, T.; Takeya, T. Direct and short-time uptake of [70]fullerene into the cell membrane using an exchange reaction from a [70]fullerene-gamma-cyclodextrin complex and the resulting photodynamic activity. Chem. Commun. (Camb.) 2009, 12, 1547-1549. [CrossRef] [PubMed]

94. Hou, W.C.; Moghadam, B.Y.; Westerhoff, P.; Posner, J.D. Distribution of fullerene nanomaterials between water and model biological membranes. Langmuir 2011, 27, 11899-11905. [CrossRef] [PubMed] 
95. Yin, X.; Zhao, L.; Kang, S.G.; Pan, J.; Song, Y.; Zhang, M.; Xing, G.; Wang, F.; Li, J.; Zhou, R.; et al. Impacts of fullerene derivatives on regulating the structure and assembly of collagen molecules. Nanoscale 2013, 5, 7341-7348. [CrossRef]

96. Bubnov, V.P.; Laukhina, E.E.; Kareev, I.E.; Koltover, V.K.; Prokhorova, T.G.; Yagubskii, E.B.; Kozmin, Y.P. Endohedral metallofullerenes: A convenient gram-scale preparation. Chem. Mater. 2002, 14, 1004-1008. [CrossRef]

97. Lakshmi, D.; Whitcombe, M.J.; Davis, F.; Sharma, P.S.; Prasad, B.B. Electrochemical detection of uric acid in mixed and clinical samples: A review. Electroanalysis 2011, 23, 305-320. [CrossRef]

98. Goel, A.; Howard, J.B.; Vander Sande, J.B. Size analysis of single fullerene molecules by electron microscopy. Carbon 2004, 42, 1907-1915. [CrossRef]

99. Dresselhaus, M.S.; Dresselhaus, G.; Eklund, P.C. Science of Fullerenes and Carbon Nanotubes: Their Properties and Applications; Elsevier Science: San Diego, CA, USA, 1996.

100. Rao, C.N.R.; Govindaraj, A.; O’Brien, P.; Kroto, H.; Craighead, H. Nanotubes and Nanowires; Royal Society of Chemistry: Cambridge, UK, 2015.

Sample Availability: Samples of the aqueous dispersions of fullerenes and endofullerene compounds are available from the authors.

(C) 2020 by the authors. Licensee MDPI, Basel, Switzerland. This article is an open access article distributed under the terms and conditions of the Creative Commons Attribution (CC BY) license (http://creativecommons.org/licenses/by/4.0/). 